Supplementary Information

\title{
Screening of Xanthine Oxidase Inhibitors by Liquid Crystal-Based Assay Assisted with Enzyme Catalysis-Induced Aptamer Release
}

WenliWu,${ }^{\dagger}{ }^{\perp}$ WeiguoWang, ${ }^{\star, \perp}$ LubinQi,${ }^{\S}$ QuanboWang,${ }^{\dagger}$ LiYu,${ }^{\S}$ Jin-MingLin ${ }^{\|}$and QiongzhengHu* ${ }^{* \dagger}$

${ }_{\dagger}^{\dagger}$ School of Pharmaceutical Sciences, Qilu University of Technology (Shandong Academy of Sciences), Jinan, 250014, China.

${ }^{\ddagger}$ School of Chemistry and Chemical Engineering, Qufu Normal University, P. R. China.

${ }^{\S}$ Key Laboratory of Colloid and Interface Chemistry, Shandong University, Ministry of Education, Jinan, 250100, China

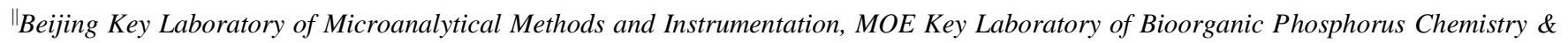
Chemical Biology, Department of Chemistry, Tsinghua University, Beijing, 100084, China.

*Corresponding author:

Qiongzheng Hu, Email: huqz@sdas.org

Table of contents

1. Experimental Section

1.1 Materials and reagents

1.2 Instruments

1.3 List of abbreviations

1.4 Preparation of the DMOAP-treated glass slides

1.5 Evaluating the inhibitory effect of potential candidates toward XOD by the UV-Vis spectroscopy

1.6 Specificity tests for the detection of XOD over other enzymes

1.7 Live/dead cell staining

1.8 Calculation of the bright area coverage ratios of the LC images

1.9 Calculation of the $Z^{\prime}$ value

\section{Supplementary data}

Figure S1. Calculation of the bright area coverage ratios of the LC images.

Figure S2. The LC images coupled to incubation of the OTAB-decorated LC interface with different concentrations of the aptamer and the aptamer/xanthine complexes.

Figure S3. The LC images coupled to incubation of the OTAB-decorated LC interface with the mixture of xanthine aptamer and guanine and the mixture of xanthine aptamer and uric acid, respectively.

Figure S4. The LC images coupled to incubation of the OTAB-decorated LC interface with different concentrations of XOD.

Figure S5. The LC images coupled to incubation of the OTAB-decorated LC interface with different enzymes and with the mixtures of aptamer, xanthine, and different enzymes, respectively.

Figure S6. The chemical structures of triazole as the potential XOD inhibitors. 
Figure S7. The optical images of the LC-based assay in response to different potential candidates toward the inhibition of XOD.

Figure S8. The inhibitory effect of the selected compounds toward XOD by the UV-Vis spectroscopy.

Figure S9. The high-throughput platform of the LC-based assay.

Figure S10.Dose response curves of (A) compound II, (B) compound III.

Figure S11. The molecular docking of (A) Compound II and XOD, (B) Compound III and XOD, respectively.

Figure S12. The MTT assay for HEK293 cells of the selected inhibitors with different concentrations.

Figure S13. Live/dead cell assay for HeLa cells.

Figure S14-S32. ${ }^{1} \mathrm{H}$ NMR spectra of the triazole derivatives used in this study. 


\section{Experimental Section}

\subsection{Materials and reagents}

40-mer single-stranded DNA ( $5^{\prime} \rightarrow 3^{\prime}$ AGCTTATTCAATTACACGACGCTCTTCCGATCTAGATTGC), tris(hydroxymethyl)aminomethane hydrochloride $(10 \mathrm{mM}$ Tris- $\mathrm{HCl}, 100 \mathrm{mM} \mathrm{NaCl}, \mathrm{pH}=8.0)$ buffer were bought from Sangon Biotech Co., Ltd., China. Uric acid (99\%) and guanine (99\%) were purchased from Aladdin Co., Ltd., China. Enzymes including xanthine oxidase (XOD), lipase, amylase, trypsin, catalase, urease, and cholesterol oxidase were supplied by Shanghai Yuanye Biological Technology Co., Ltd., China. 4-cyano-4'-pentylbiphenyl (5CB, 98\%) and trimethyloctadecylammonium bromide (OTAB, 99\%) were purchased from J\&K Scientific Co., Ltd., China. N, N-Dimethyl-N-octadecyl(3-aminopropyl)trimethoxysilyl chloride (DMOAP, 60 wt\% solution in $\mathrm{MeOH}$ ) was provided by Energy Chemical Co., Ltd., China. Copper specimen grids (G75 with hole pitch of $340 \mu \mathrm{m}$, bar width of $55 \mu \mathrm{m}$, hole width of $285 \mu \mathrm{m}$ ) were supplied by GILDER. The live/dead staining kit was provided by Shanghai BestBio Biotechnology Co., Ltd, Shanghai, China.

\subsection{Instruments}

The optical images of LCs were obtained by a polarized light microscope (POM, XPF-800C, Tianxing, Shanghai, China) with a $2.5 \times$ objective lens and a digital camera (TK-9301 EC, JVC, Japan). The UV-Vis spectra were measured by a Hitachi U-2910 spectrophotometer. Cell imaging was conducted with a confocal microscope (Leica TCS SP8 STED).

\subsection{List of abbreviations}

\begin{tabular}{cccc}
$\begin{array}{c}\text { Abbrevia- } \\
\text { tion }\end{array}$ & Name & $\begin{array}{c}\text { Abbrevia- } \\
\text { tion }\end{array}$ & Name \\
\hline LCs & liquid crystals & DMEM-H & Dulbecco's Modified Eagle Medium \\
XOD & xanthine oxidase & FBS & Fetal Bovine Serum \\
OTAB & octadecyl trimethyl ammonium bromide & MTT & Methylthiazolyldiphenyl-tetrazo- \\
& & & lium bromide \\
$5 \mathrm{CB}$ & $4-$ cyano-4'-pentylbiphenyl & SD & Standard Deviation
\end{tabular}


$\begin{array}{lll}\text { DMOAP } & \mathrm{N}, \mathrm{N} \text {-Dimethyl-N-octadecyl(3-aminopropyl)tri- } \\ \text { methoxysilyl chloride } & \text { PI } & \text { propidium iodide }\end{array}$

Brs bright coverage area ratios

\subsection{Preparation of the DMOAP-treated glass slides}

The glass slides were treated as the following procedures. Firstly, the glass slides were cleaned thoroughly by soaking in "piranha solution" $\left(70 \% \mathrm{H}_{2} \mathrm{SO}_{4} / 30 \% \mathrm{H}_{2} \mathrm{O}_{2}\right.$, v/v) at $75^{\circ} \mathrm{C}$ for $30 \mathrm{~min}$. Then, the glass slides were washed with plenty of ultrapure water, ethanol, and methanol in sequence. Afterwards, the glass slides were dried under flowing nitrogen and kept in the oven at $120{ }^{\circ} \mathrm{C}$ overnight. To obtain the DMOAP-treated glass slides, the glasses were soaked in 1.0 vol\% DMOAP solution for 20 min, washed with ultrapure water, and dried under the stream of nitrogen. Finally, the glass slides were ready to be used in the LC-based assay.

\subsection{Evaluating the inhibitory effect of potential candidates toward XOD by the UV-Vis spectros- copy}

All solutions were prepared in $10 \mathrm{mM}$ Tris- $\mathrm{HCl}(100 \mathrm{mM} \mathrm{NaCl}, \mathrm{pH} 8.0) .60 \mu \mathrm{L}$ of the potential inhibitor solution and $60 \mu \mathrm{L}$ of XOD solution were added into a centrifuge tube and incubated for $60 \mathrm{~min}$. The mixture was then incubated at $25^{\circ} \mathrm{C}$ for $60 \mathrm{~min}$ after an aliquot of $500 \mu \mathrm{M}$ xanthine was added. Then, after dilution by proper times with buffer, the mixture solution was measured by the UV-Vis spectroscopy.

\subsection{Specificity tests for the detection of XOD over other enzymes}

The mixture of tested enzyme and xanthine in $10 \mathrm{mM}$ Tris- $\mathrm{HCl}$ buffer $(100 \mathrm{mM} \mathrm{NaCl}, \mathrm{pH}=8.0)$ was pre-incubated at $25^{\circ} \mathrm{C}$ for $60 \mathrm{~min}$, followed by incubation of the mixture with the aptamer for $60 \mathrm{~min}$. Next, $40 \mu \mathrm{L}$ of the mixed solution was transferred into the optical cell. The optical images of LCs were taken after incubation for $20 \mathrm{~min}$. The concentration of individual enzymes was 1 $\mu \mathrm{g} / \mathrm{mL}$. The data are presented as mean $\pm \mathrm{SD}(\mathrm{n} \geqslant 3)$.

\subsection{Live/dead cell staining}

To determine whether the potential inhibitors were biocompatible, the cells were stained after incubation using the live/dead staining kit according to the protocol provided by BestBio. Briefly, Calcein-AM 
and PI were added into the culture medium successively. After incubation for 20 min under the dark condition, the cells were imaged under the confocal microscopy.

\subsection{Calculation of the bright area coverage ratios of the LC images}

The bright area coverage ratio $(B r)$ was calculated following the equation as below:

$\mathrm{Br} \%=$ pixels of the bright area/pixels of the entire $5 \mathrm{CB}$ region;

pixels of the entire $5 \mathrm{CB}$ region = pixels of the entire copper grid region-pixels of grid spacing;

\subsection{Calculation of the $Z^{\prime}$ value}

$$
Z^{\prime}=1-\frac{\left|3 \sigma_{c+}+3 \sigma_{c-}\right|}{\left|\mu_{c+}-\mu_{c-}\right|}
$$

in which: $\sigma_{\mathrm{c}+}$ : the $\mathrm{SD}$ of positive control signals

$$
\begin{aligned}
& \sigma_{\mathrm{c}-}: \text { the SD of negative control signals } \\
& \mu_{\mathrm{c}+} \text { : the mean of positive control signals } \\
& \mu_{\mathrm{c}-} \text { : the mean of negative control signals }
\end{aligned}
$$

Taken the uniform bright images as positive controls, 97.7, 100, 100, 100, 100, 100;

Taken the uniform dark images as negative controls: the Brs are 3.2, 0, 0, 1.2, 9.8, 21.2.

Therefore, $\sigma_{\mathrm{c}+}=7.62 ; \sigma_{\mathrm{c}-}=0.85 ; \mu_{\mathrm{c}+}=99.6 ; \mu_{\mathrm{c}-}=5.9$.

$$
Z^{\prime}=1-\frac{\mid 3 \sigma_{c \tau+3 \sigma_{c-} \mid}}{\left|\mu_{c+}-\mu_{c-}\right|}=1-\frac{|3 \times 7.62+3 \times 0.85|}{|99.6-5.9|}=0.729 ; \text { The final } Z^{\prime} \text { was determined as } 0.78 \pm 0.2 \text { for six }
$$

repeats.

Therefore, the result indicates that the assay conditions have been optimized.

\section{Supplementary data and discussion}
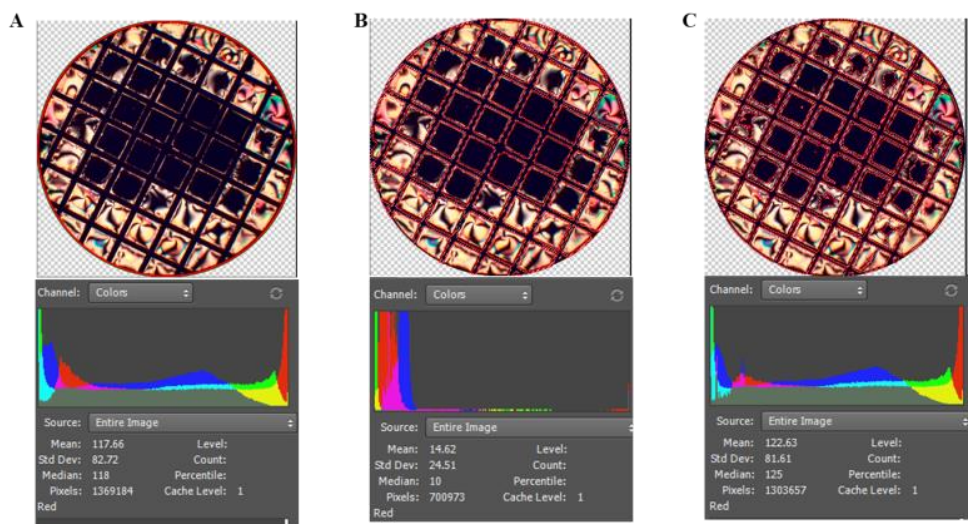

Figure S1. Calculation of the bright area coverage ratios of the LC images: (A) selection of the entire copper grid region, (B) selection of the grid spacing, (C) selection of the entire 5CB region. 


\section{A Aptamer}

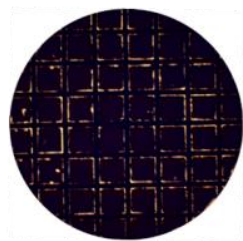

0

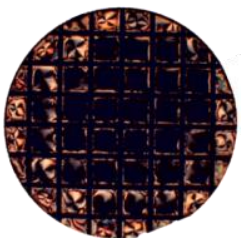

$1 \mu \mathrm{M}$

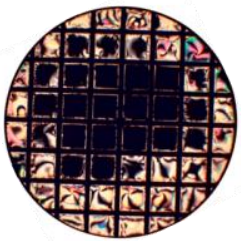

$2 \mu \mathrm{M}$

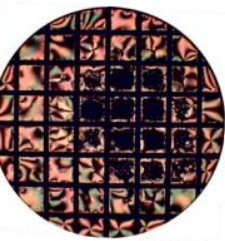

$3 \mu \mathrm{M}$

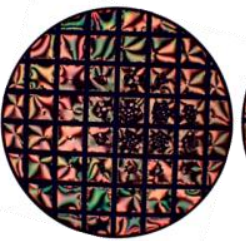

$4 \mu \mathrm{M}$

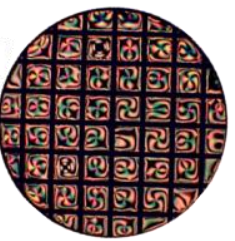

$5 \mu \mathrm{M}$

\section{B Aptamer +xanthine}

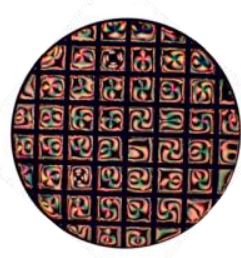

0

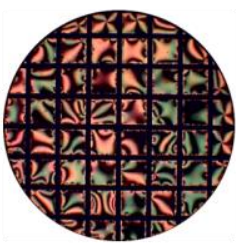

$100 \mu \mathrm{M}$

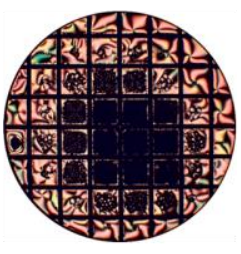

$200 \mu \mathrm{M}$

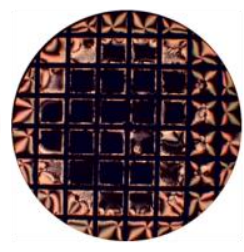

$300 \mu \mathrm{M}$

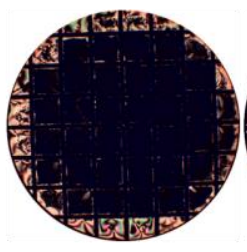

$400 \mu \mathrm{M}$

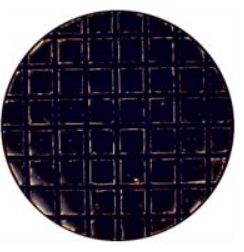

$500 \mu \mathrm{M}$

Figure S2. The LC images coupled to incubation of the OTAB-decorated LC interface with different concentrations of $(\mathrm{A})$ the aptamer $(0-5 \mu \mathrm{M})$ and $(\mathrm{B})$ the aptamer/xanthine complexes consisting of the aptamer $(5 \mu \mathrm{M})$ and different concentrations of xanthine $(0-500 \mu \mathrm{M})$.
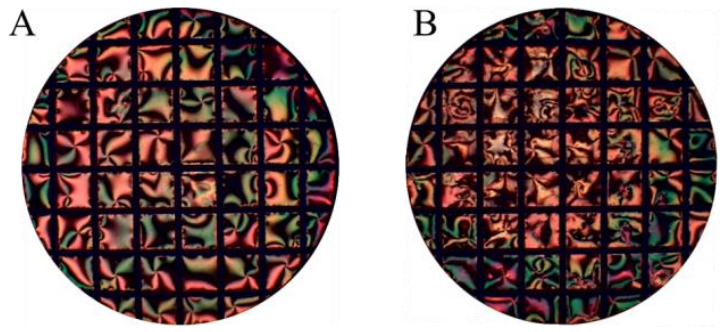

Figure S3. The LC images coupled to incubation of the OTAB-decorated LC interface with (A) the mixture of xanthine aptamer $(5 \mu \mathrm{M})$ and guanine $(500 \mu \mathrm{M})$ and $(\mathrm{B})$ the mixture of xanthine aptamer $(5 \mu \mathrm{M})$ and uric acid $(500 \mu \mathrm{M})$, respectively.
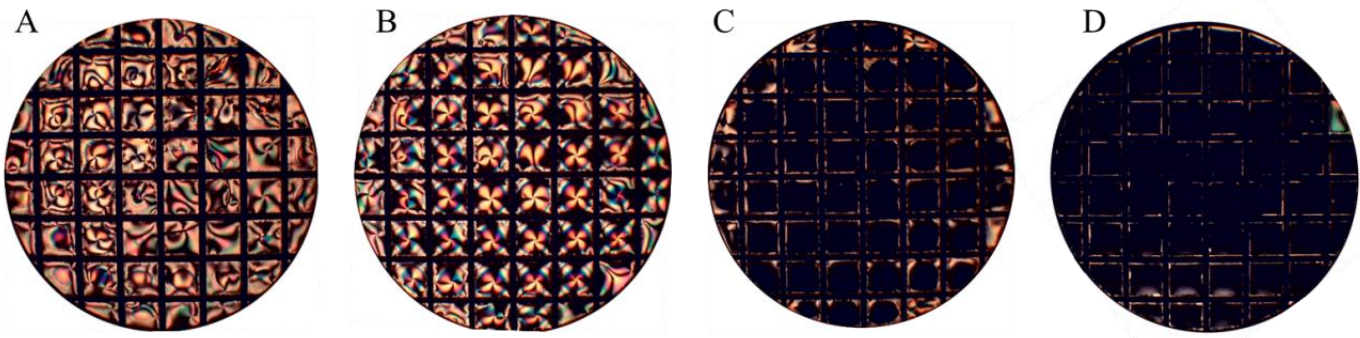

Figure S4. The LC images coupled to incubation of the OTAB-decorated LC interface with different concentrations of XOD: (A) $100 \mu \mathrm{g} / \mathrm{mL}$, (B) $10 \mu \mathrm{g} / \mathrm{mL}$, (C) $5 \mu \mathrm{g} / \mathrm{mL}$, and (D) $1 \mu \mathrm{g} / \mathrm{mL}$, respectively. 
Different enzymes
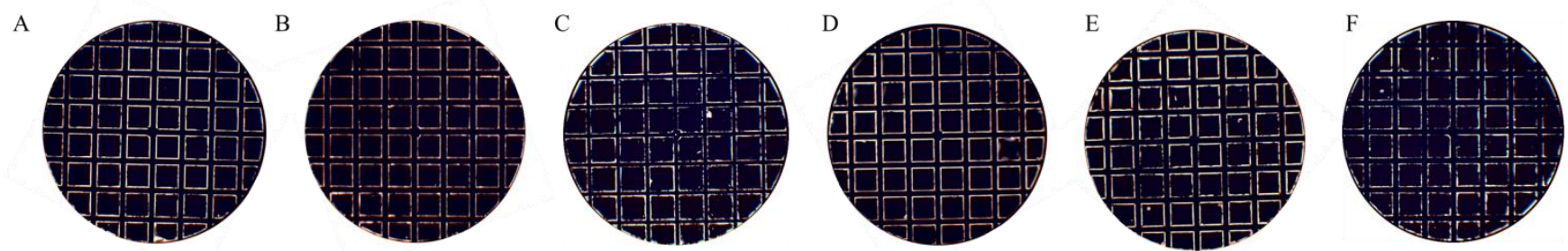

Aptamer + xanthine + different enzymes
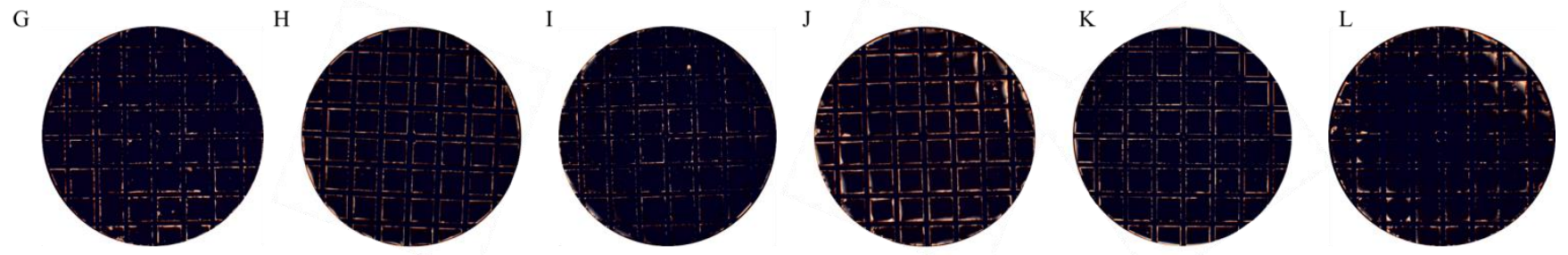

Figure S5. The LC images coupled to incubation of the OTAB-decorated LC interface with different enzymes (1 $\mu \mathrm{g} / \mathrm{mL})$ and with the mixtures of aptamer $(5 \mu \mathrm{M})$, xanthine $(500 \mu \mathrm{M})$, and different enzymes $(1 \mu \mathrm{g} / \mathrm{mL})$. (A) and (G): lipase; (B) and (H): amylase; (C) and (I): trypsin; (D) and (J): catalase; (E) and (K): urease; (F) and (L): cholesterol oxidase.

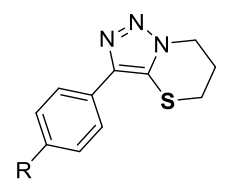
1, $\mathrm{R}=\mathrm{H}$
2, $\mathrm{R}=\mathrm{Me}$
3, $\mathrm{R}=\mathrm{OMe}$
4, $\mathrm{R}=\mathrm{Br}$
5, $\mathrm{R}=\mathrm{CF}_{3}$
6, $\mathrm{R}=\mathrm{CO}_{2} \mathrm{Me}$

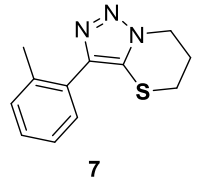<smiles>O=[N+]([O-])c1cccc(-c2nnc3n2CCC3)c1</smiles>
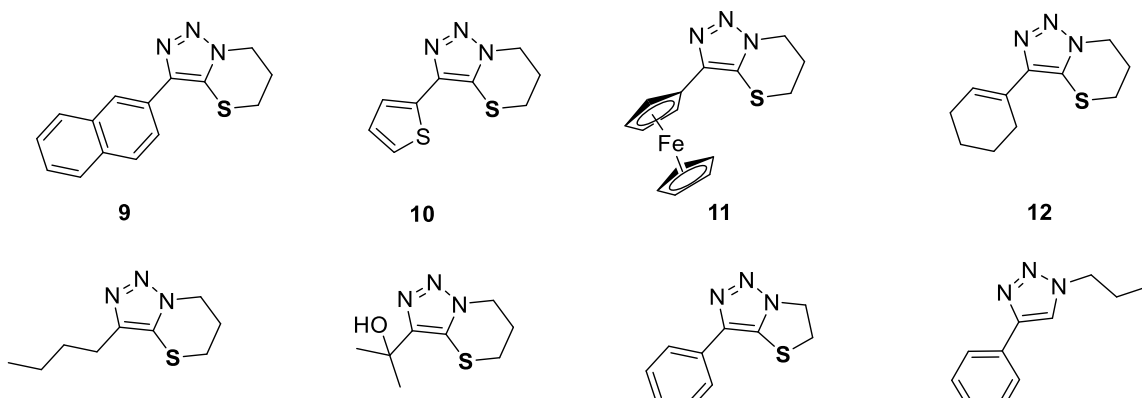

14

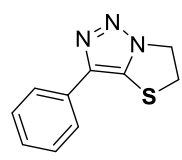

15

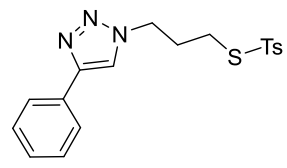

16

Figure S6. The chemical structures of triazoles as the potential XOD inhibitors. 


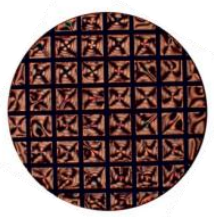

1

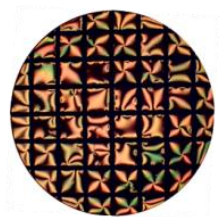

6

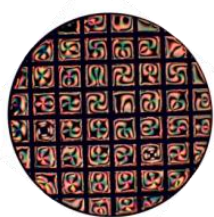

11

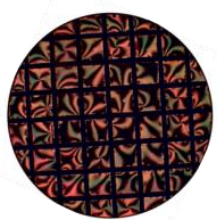

16

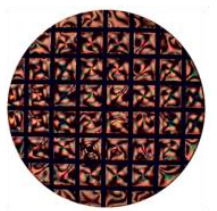

2

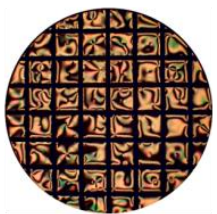

7

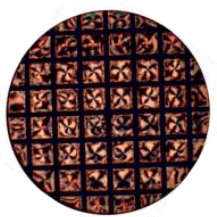

12

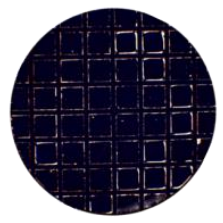

I

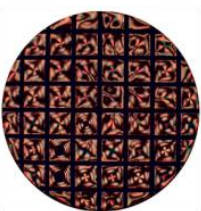

3

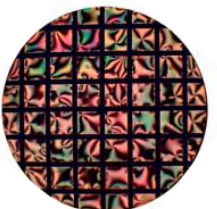

8

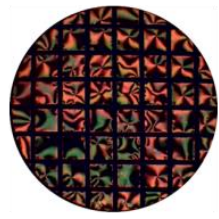

13

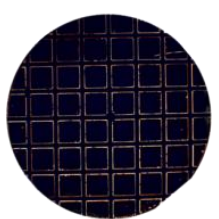

II

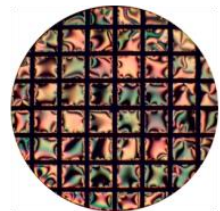

4

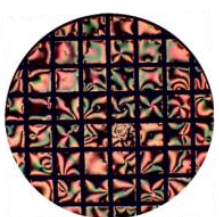

9

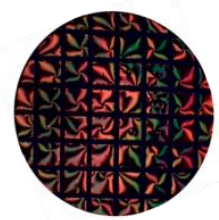

14

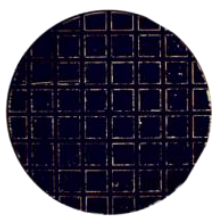

III
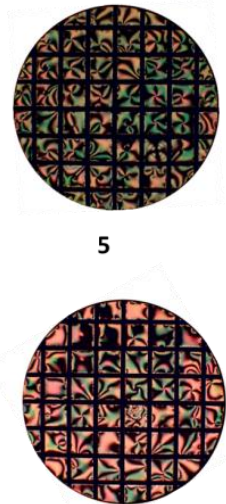

10

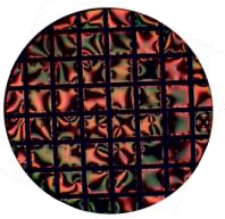

15

Figure S7. The optical images of the LC-based assay in response to different potential candidates toward the inhibition of XOD. For the stock solution, DMSO (0.5 vol\%) was used as cosolvent.
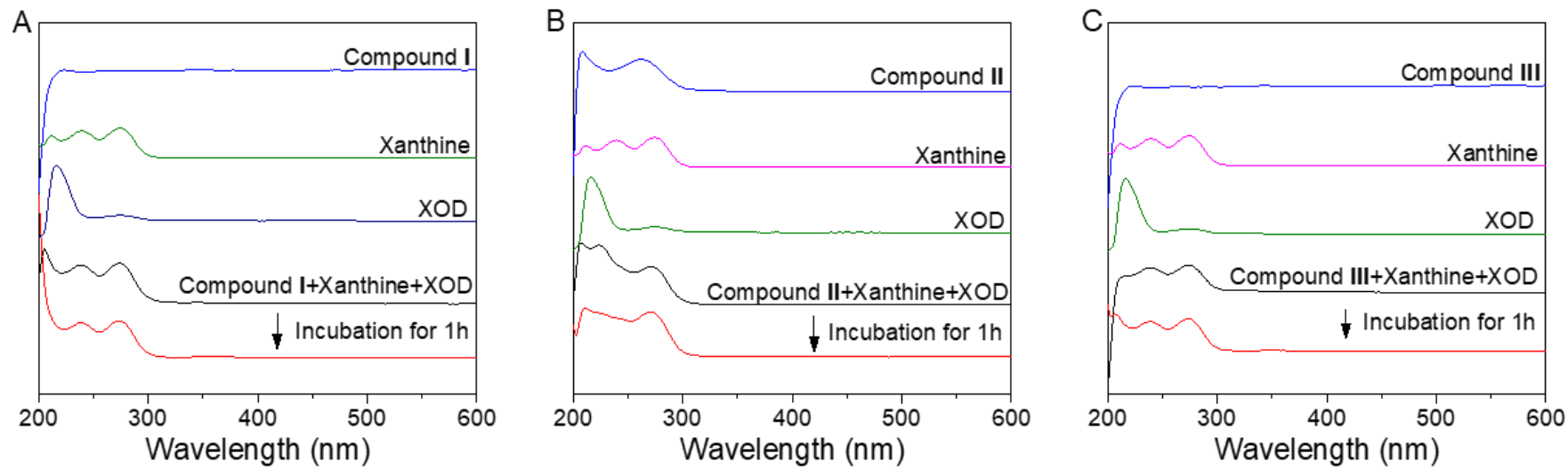

Figure S8. The inhibitory effect of the selected compounds toward XOD by the UV-Vis spectroscopy. To eliminate the absorption disturbance, concentrations of xanthine and potential candidates were optimized respectively at the beginning of the experiment. The final concentrations of the potential candidates were $0.375 \mathrm{mg} / \mathrm{mL}$ and the other tested conditions were same as those applied in Figure 4B. 


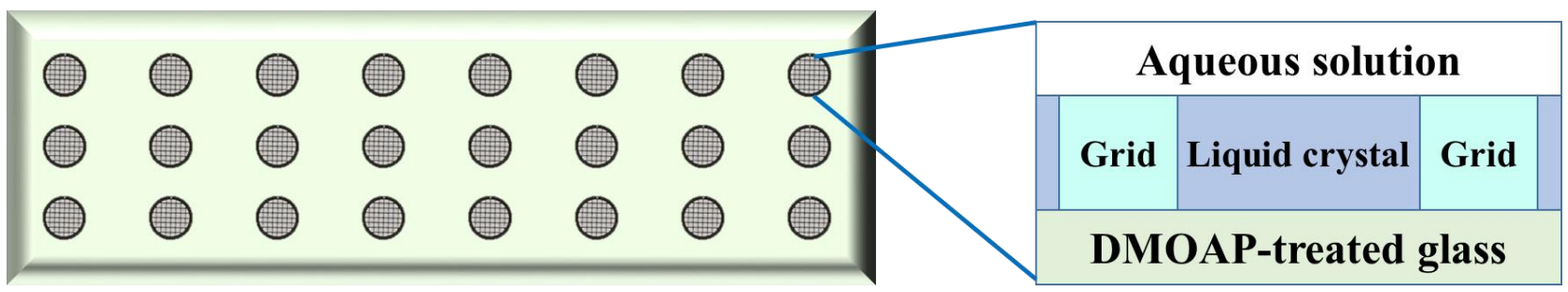

Figure S9. The high-throughput platform of the LC-based assay. The dimension of the glass slide was $75 \mathrm{~mm} \times 25$ mm (length $\times$ width).
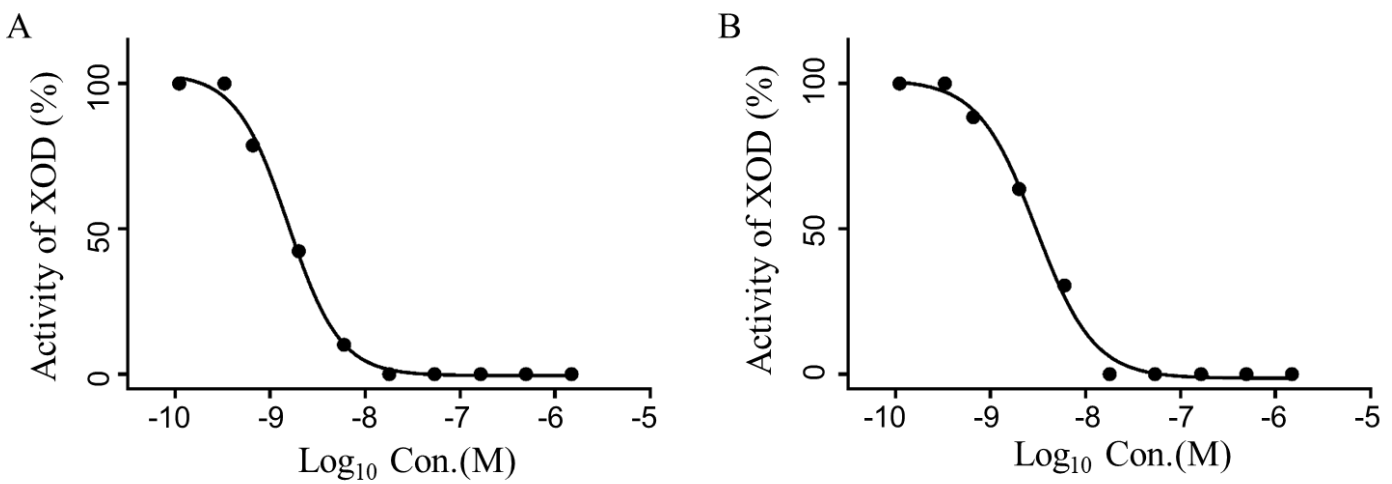

Figure S10. Dose response curves of (A) compound II, (B) compound III, respectively. The pIC $\mathrm{C}_{50}$ values for compound II and III were determined to be $8.69 \pm 0.10$, and $8.54 \pm 0.14$, respectively. The data are presented as mean \pm $\mathrm{SD}(\mathrm{n} \geqslant 3)$.
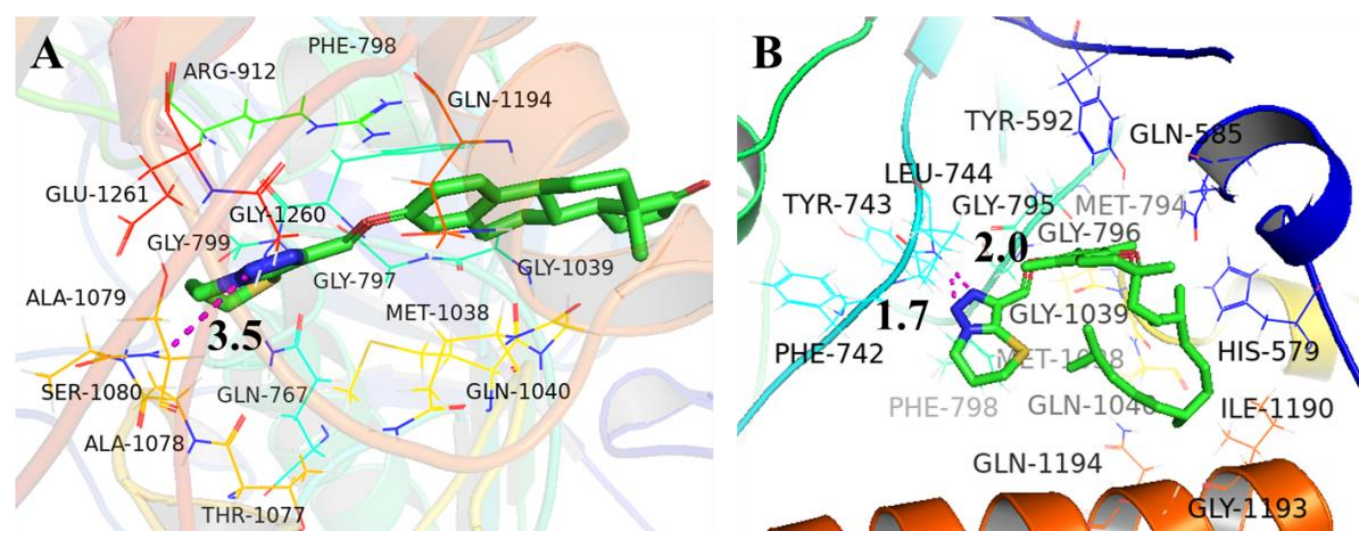

Figure S11. The molecular docking of (A) Compound II and XOD, (B) Compound III and XOD, respectively. A hydrogen bond was also formed between the $\mathrm{H}$ atom of Ser1080 residue and the $\mathrm{N}$ atom of heterocyclic rings of triazole of II with bond distance 3.5 $\AA$. Two hydrogen bonds with bond distances of $1.7 \AA$ and $2.0 \AA$ were formed between the $\mathrm{H}$ atom of Leu 744 residue and the $\mathrm{N}$ atom of heterocyclic rings of triazole of III, respectively. 


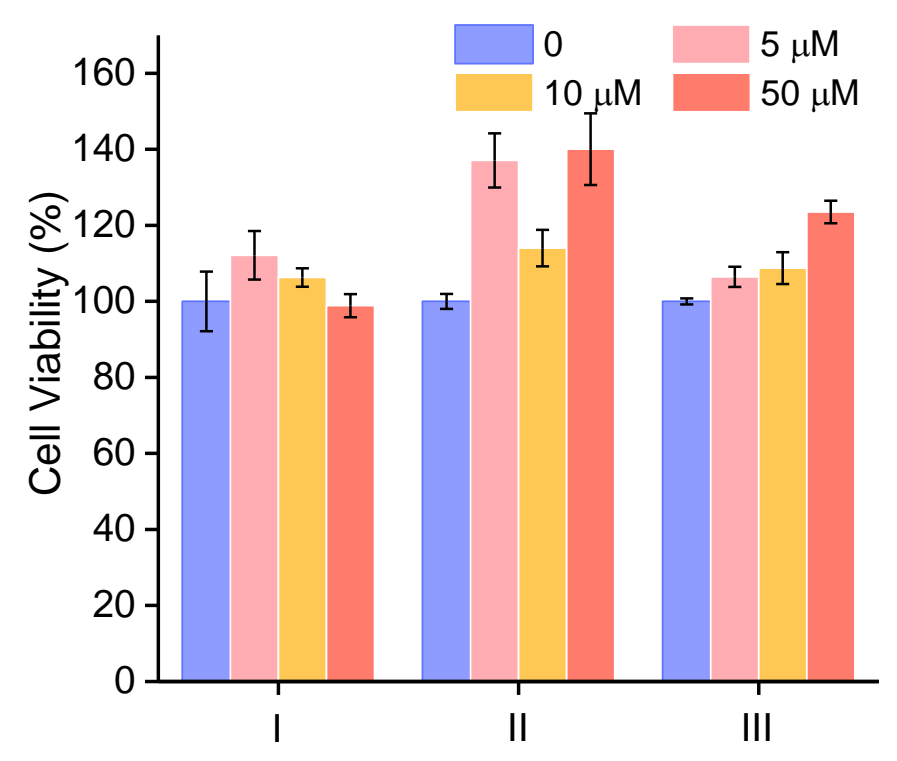

Figure S12. The MTT assay for HEK293 cells of the selected inhibitors with different concentrations $(0,5,10,50$ $\mu \mathrm{M})$ for $48 \mathrm{~h}$. The data are presented as mean $\pm \mathrm{SD}(\mathrm{n} \geqslant 3)$.

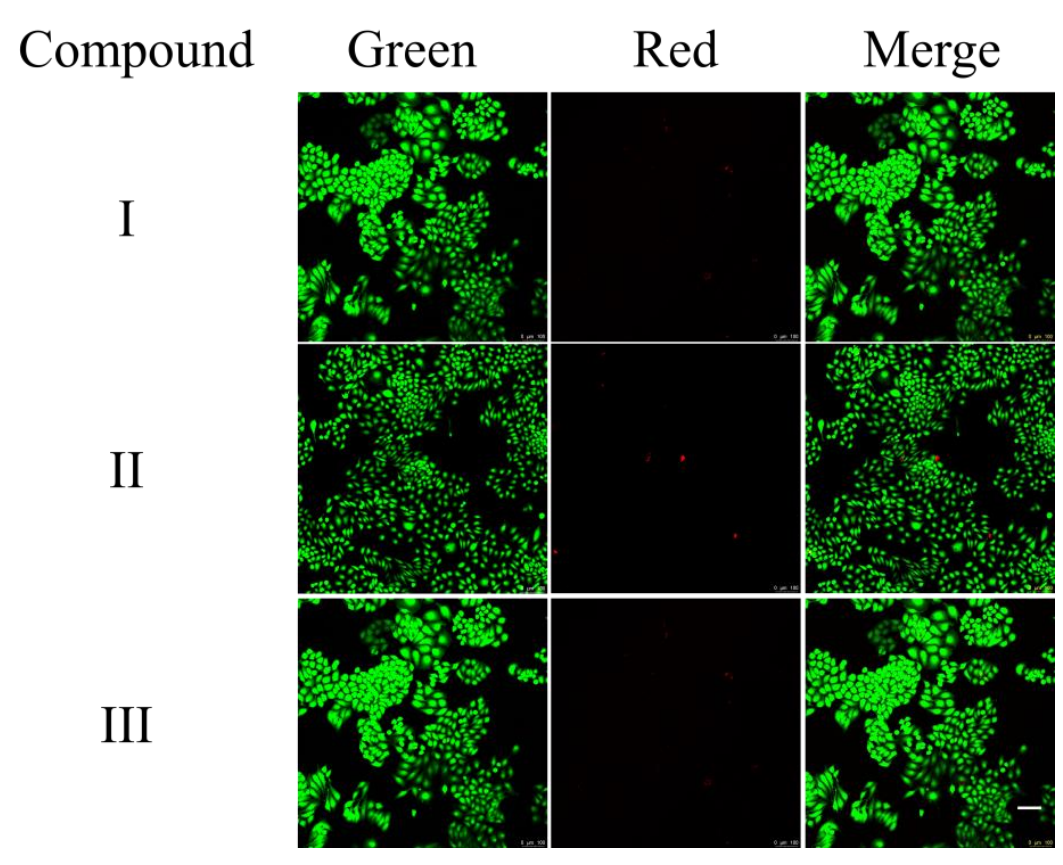

Figure S13. Live/dead cell assay for HeLa cells. Cells were stained with calcein (live cells, green) and PI (dead cells, red). The first, second, and third row represented compound I, II, and III, respectively. Green channel (500$540 \mathrm{~nm})$; Red channel (600-650 nm). Scale bar: $100 \mu \mathrm{m}$. 

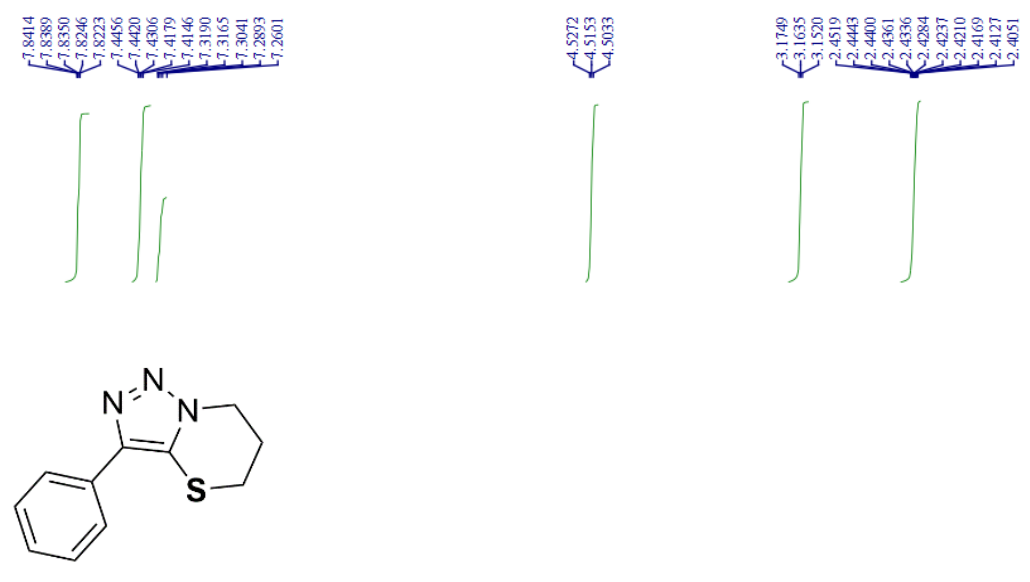

1

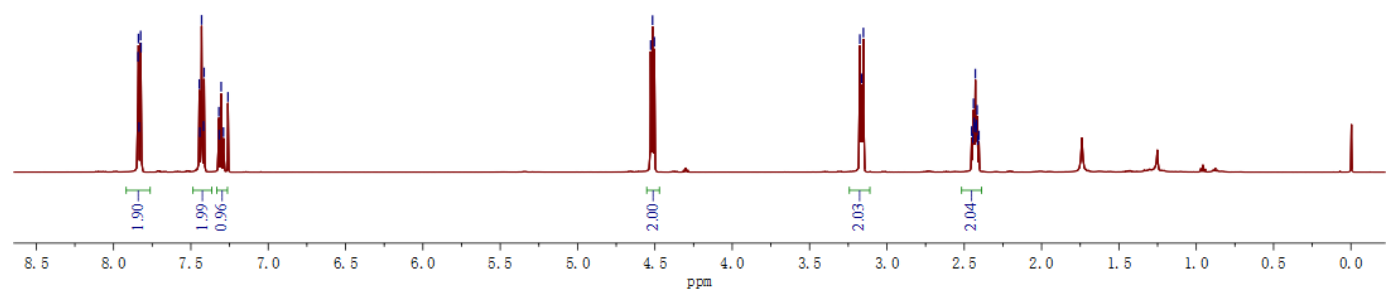

Figure S14. ${ }^{1} \mathrm{H}$ NMR spectrum of compound 1.
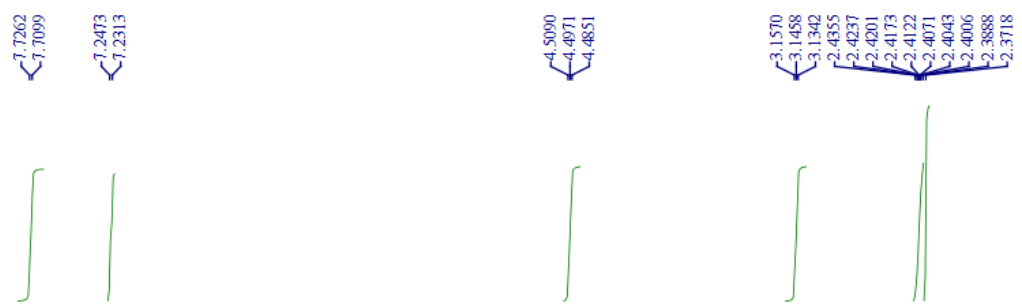

†

लं
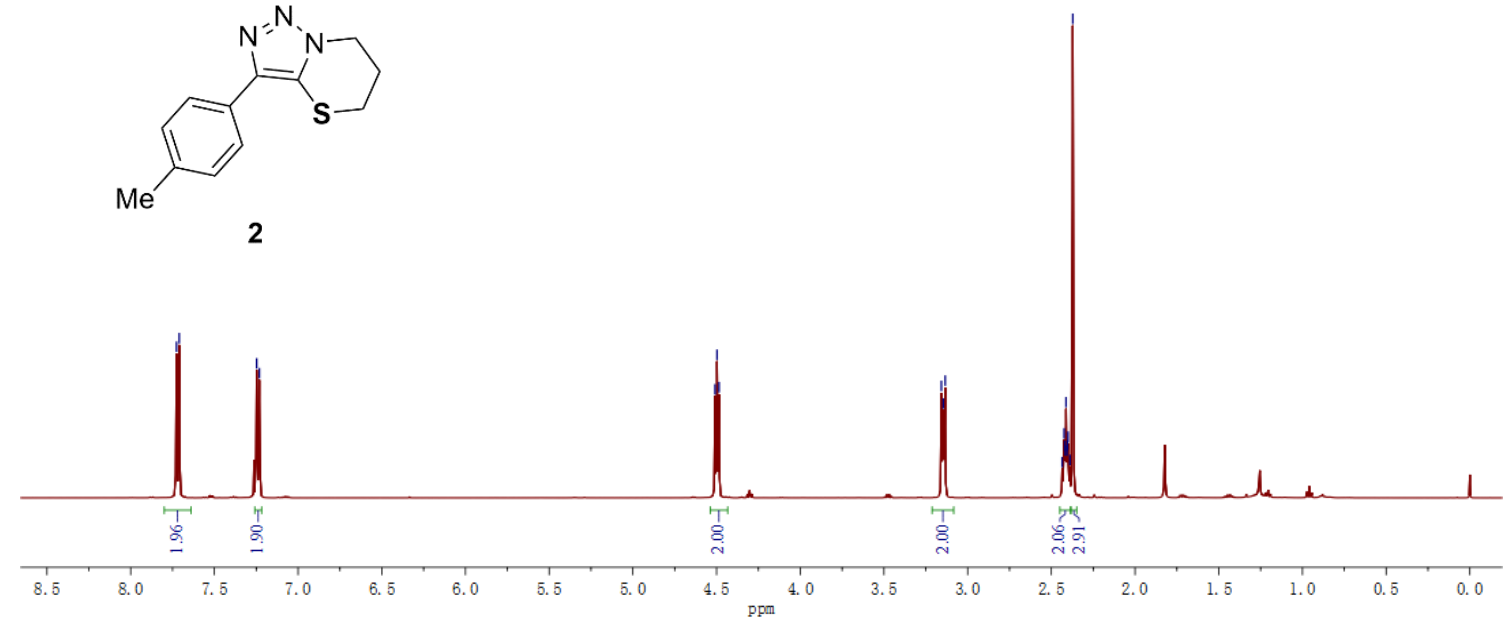

Figure S15. ${ }^{1} \mathrm{H}$ NMR spectrum of compound 2. 


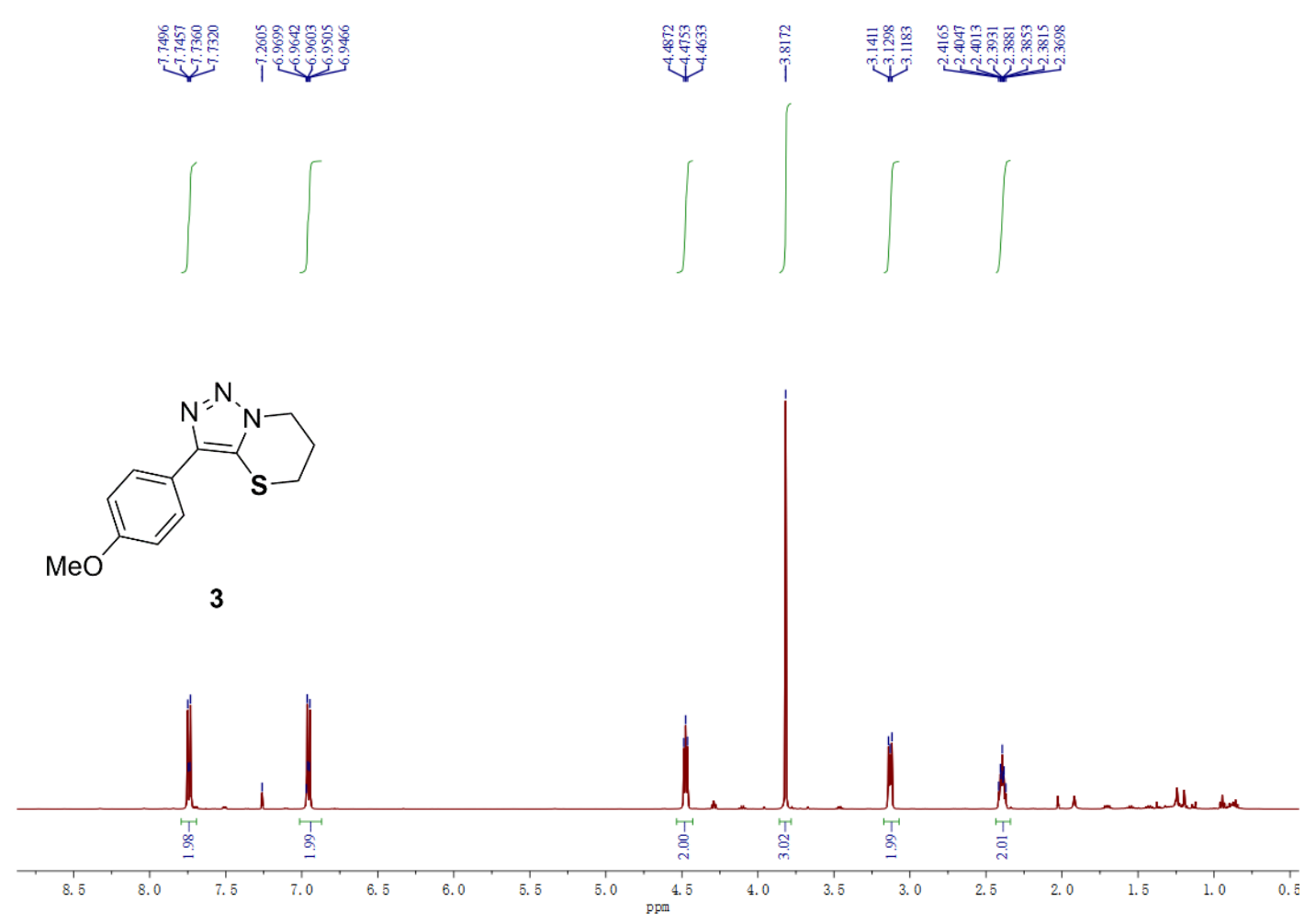

Figure S16. ${ }^{1} \mathrm{H}$ NMR spectrum of compound 3.

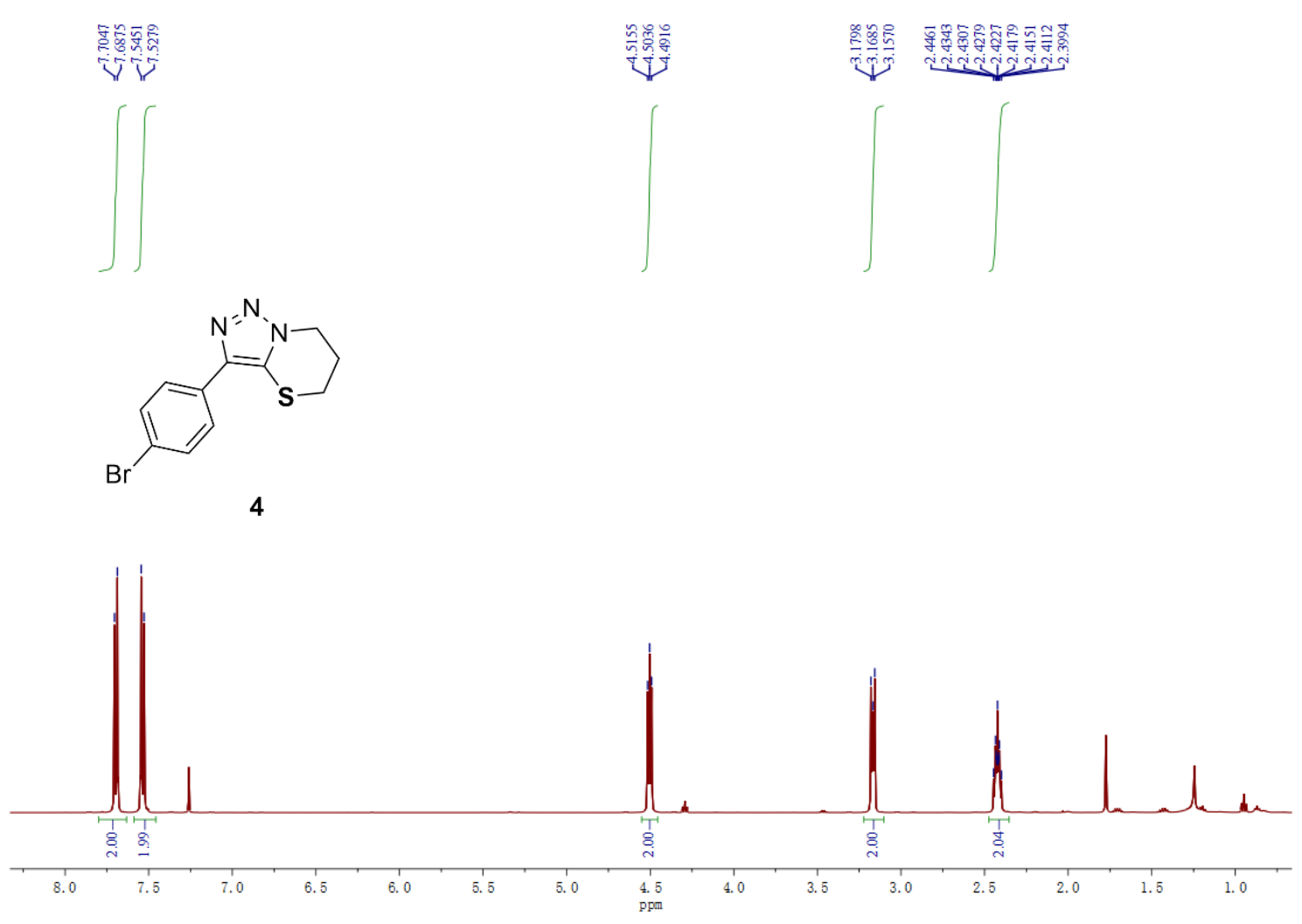

Figure S17. ${ }^{1} \mathrm{H}$ NMR spectrum of compound 4. 


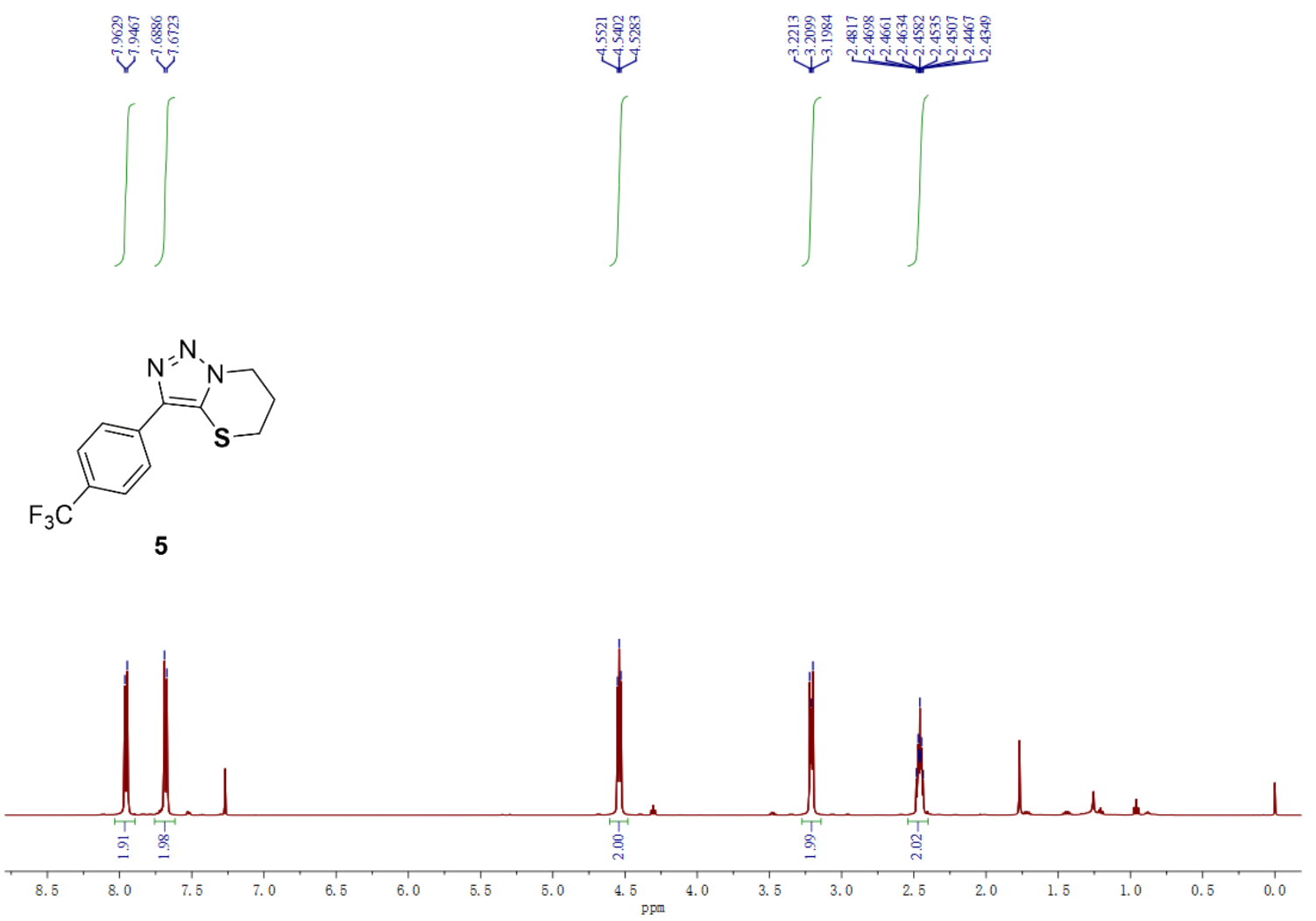

Figure S18. ${ }^{1} \mathrm{H}$ NMR spectrum of compound 5.

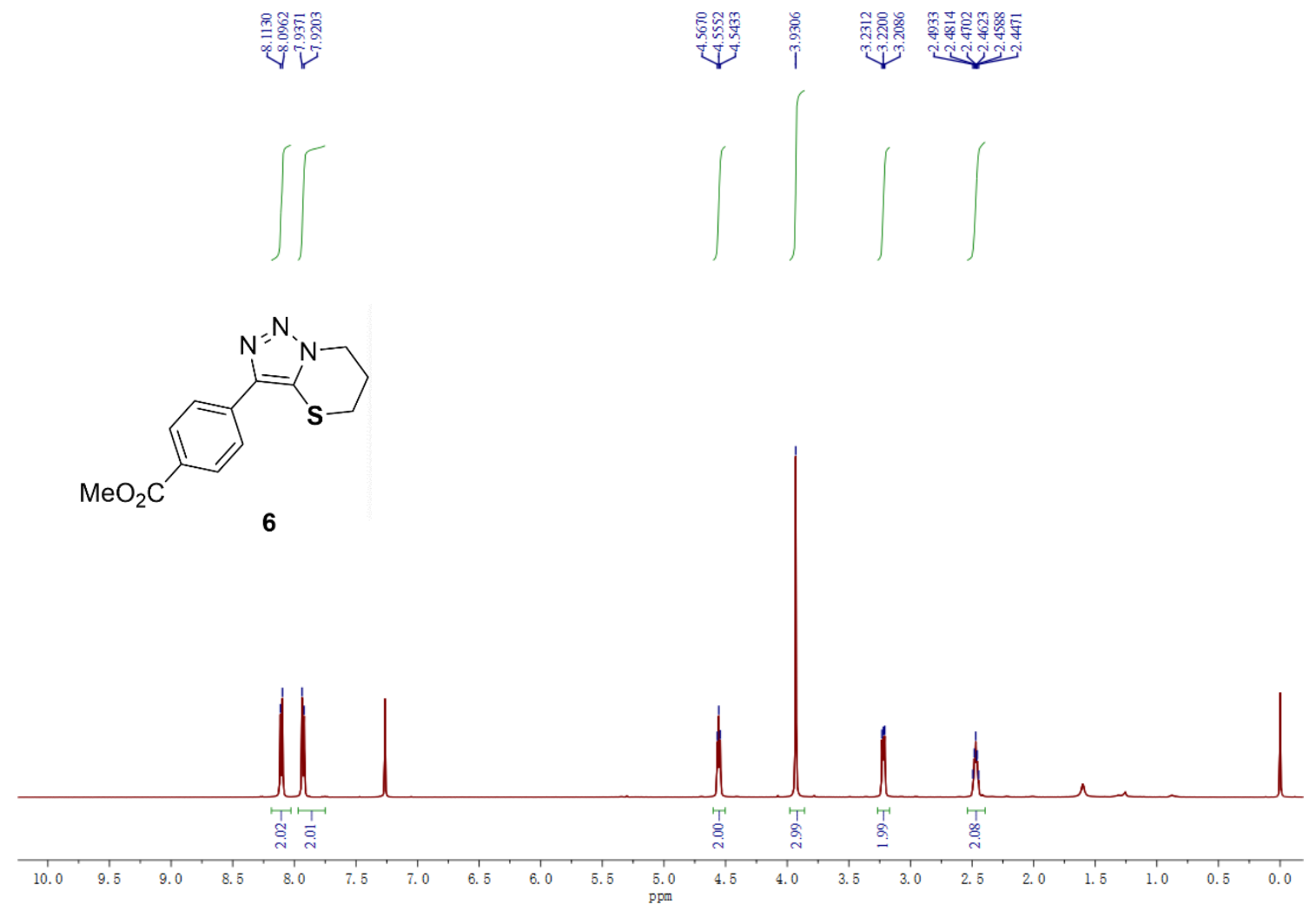

Figure S19. ${ }^{1} \mathrm{H}$ NMR spectrum of compound 6. 


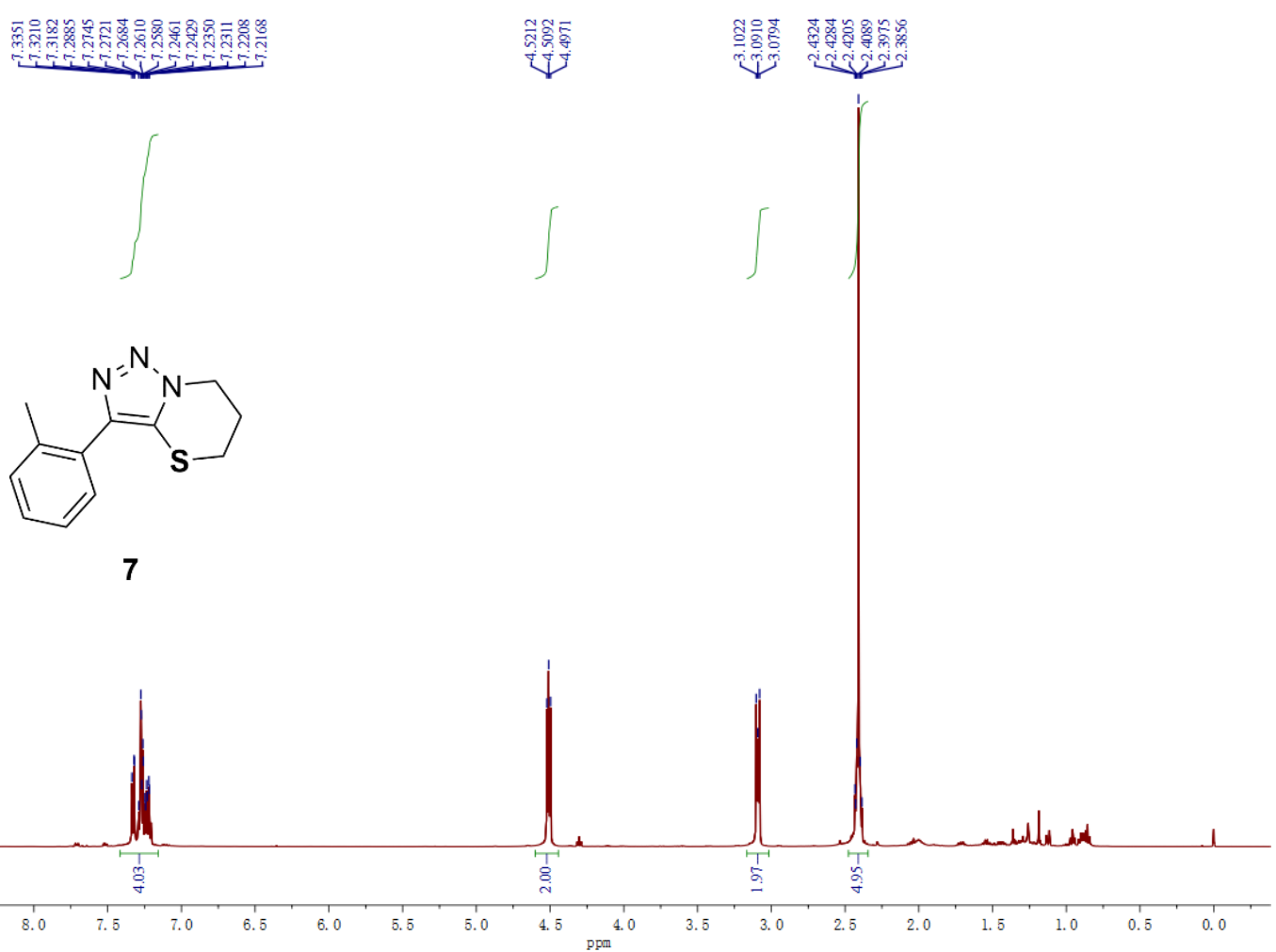

Figure S20. ${ }^{1} \mathrm{H}$ NMR spectrum of compound 7.

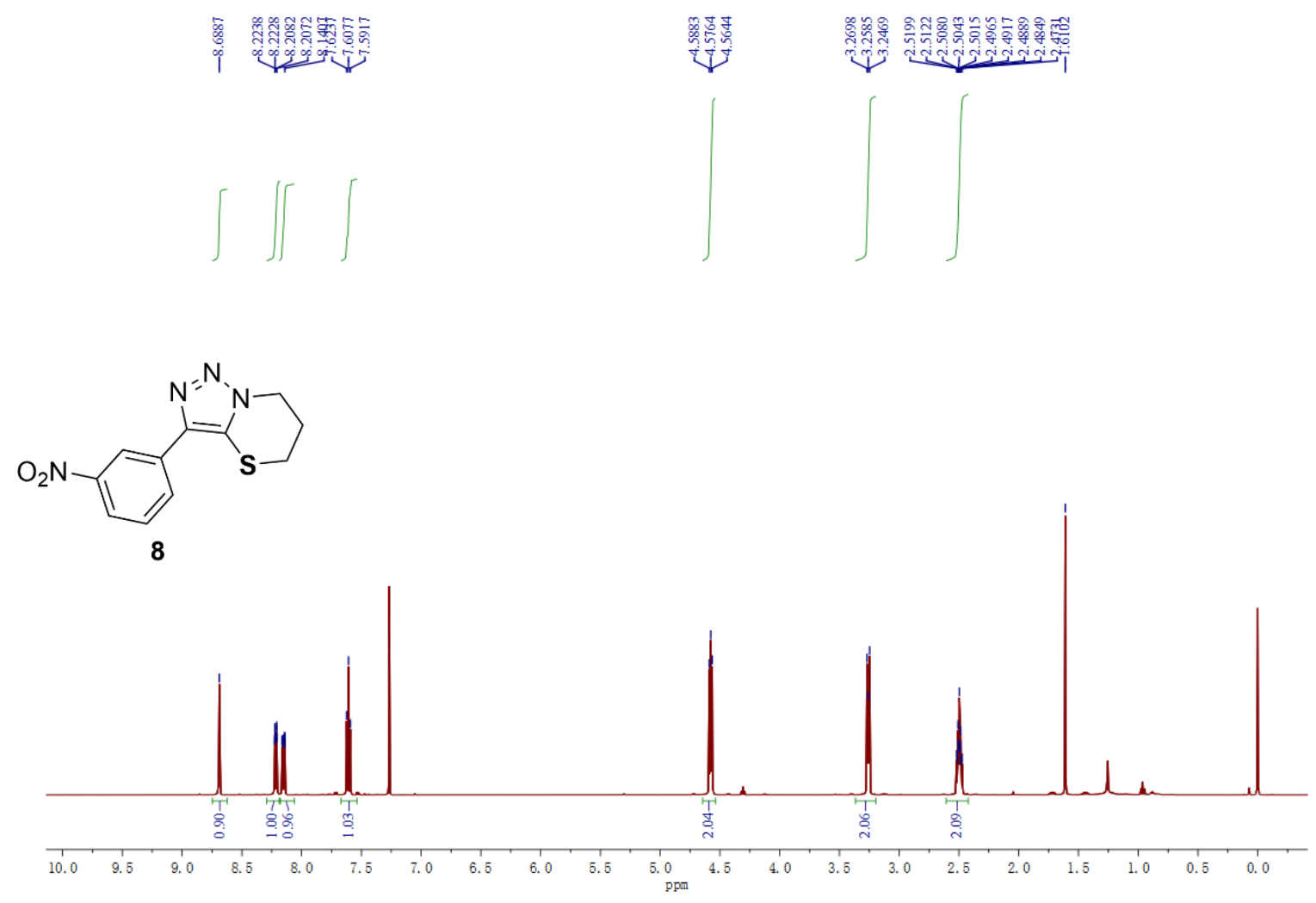

Figure S21. ${ }^{1}$ H NMR spectrum of compound 8. 

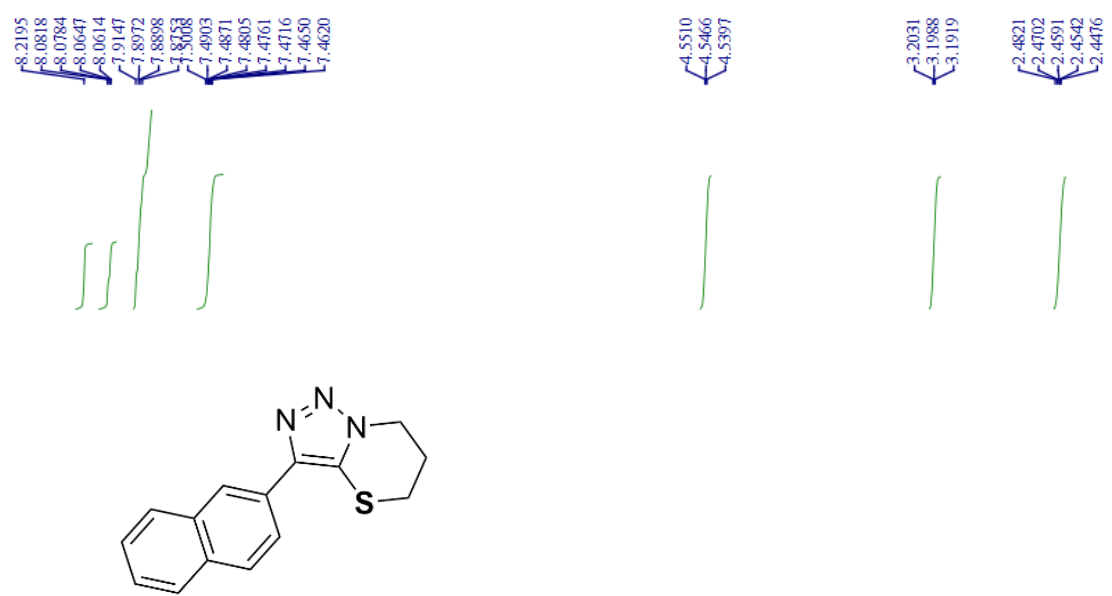

9

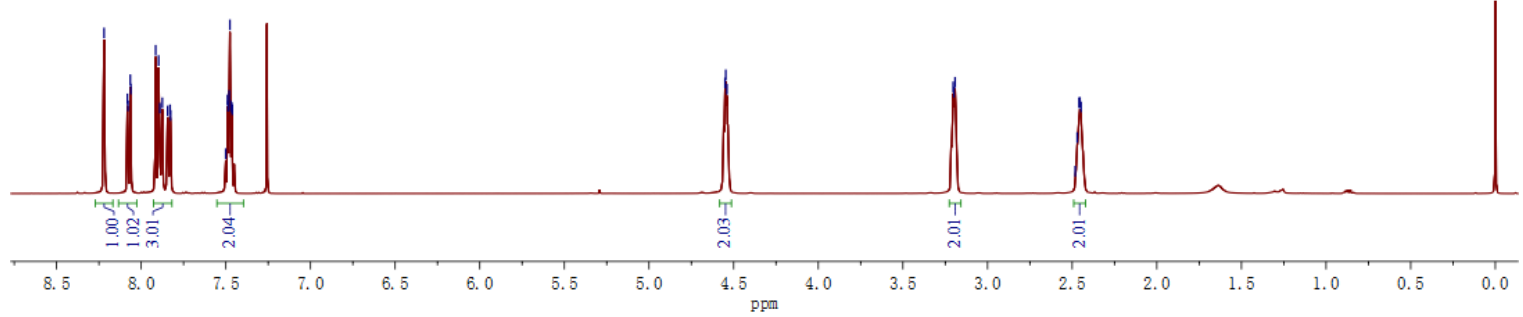

Figure S22. ${ }^{1} \mathrm{H}$ NMR spectrum of compound 9.
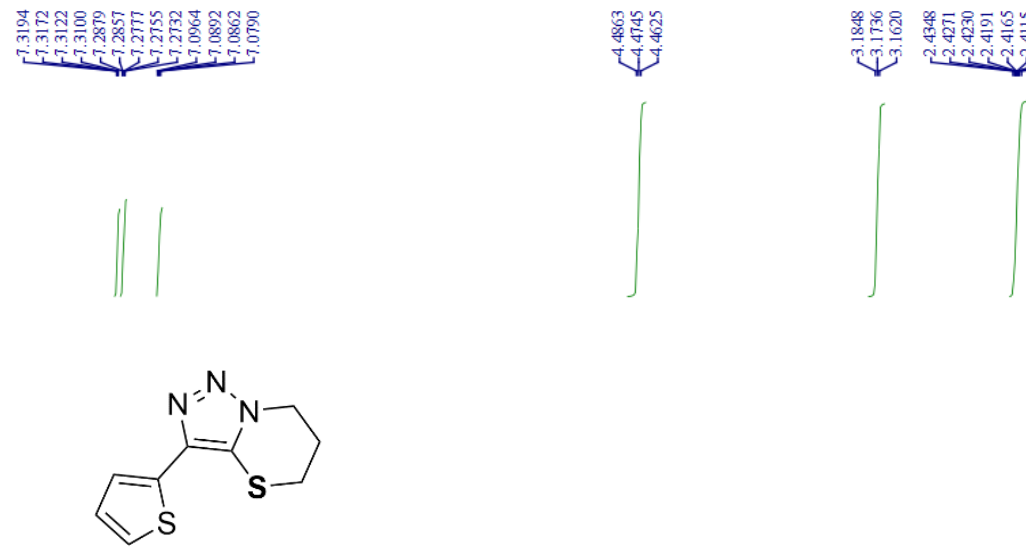

10

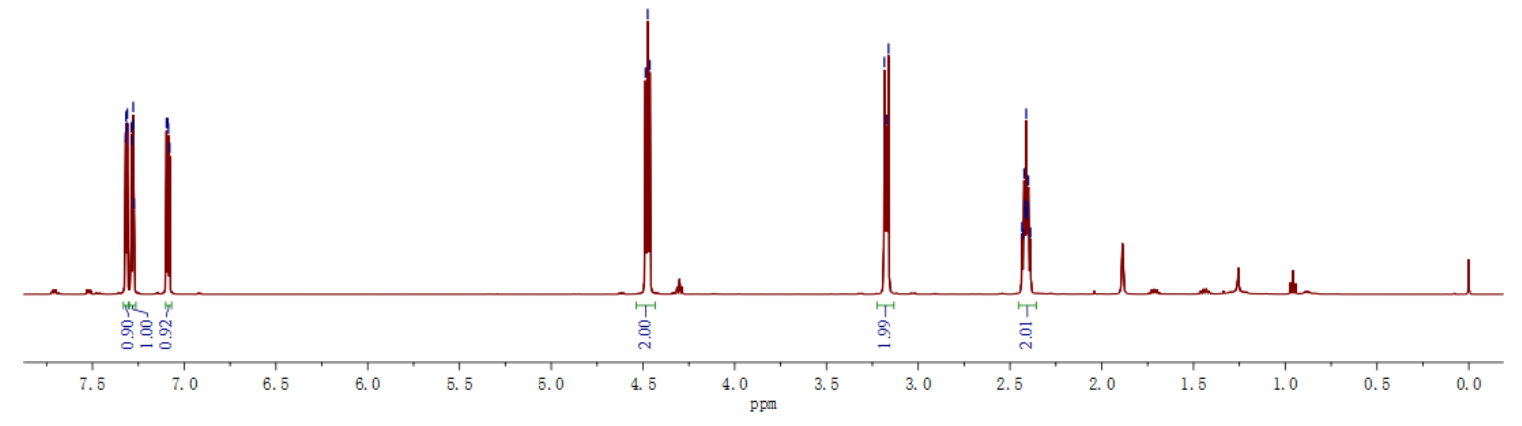

Figure S23. ${ }^{1} \mathrm{H}$ NMR spectrum of compound $\mathbf{1 0}$. 

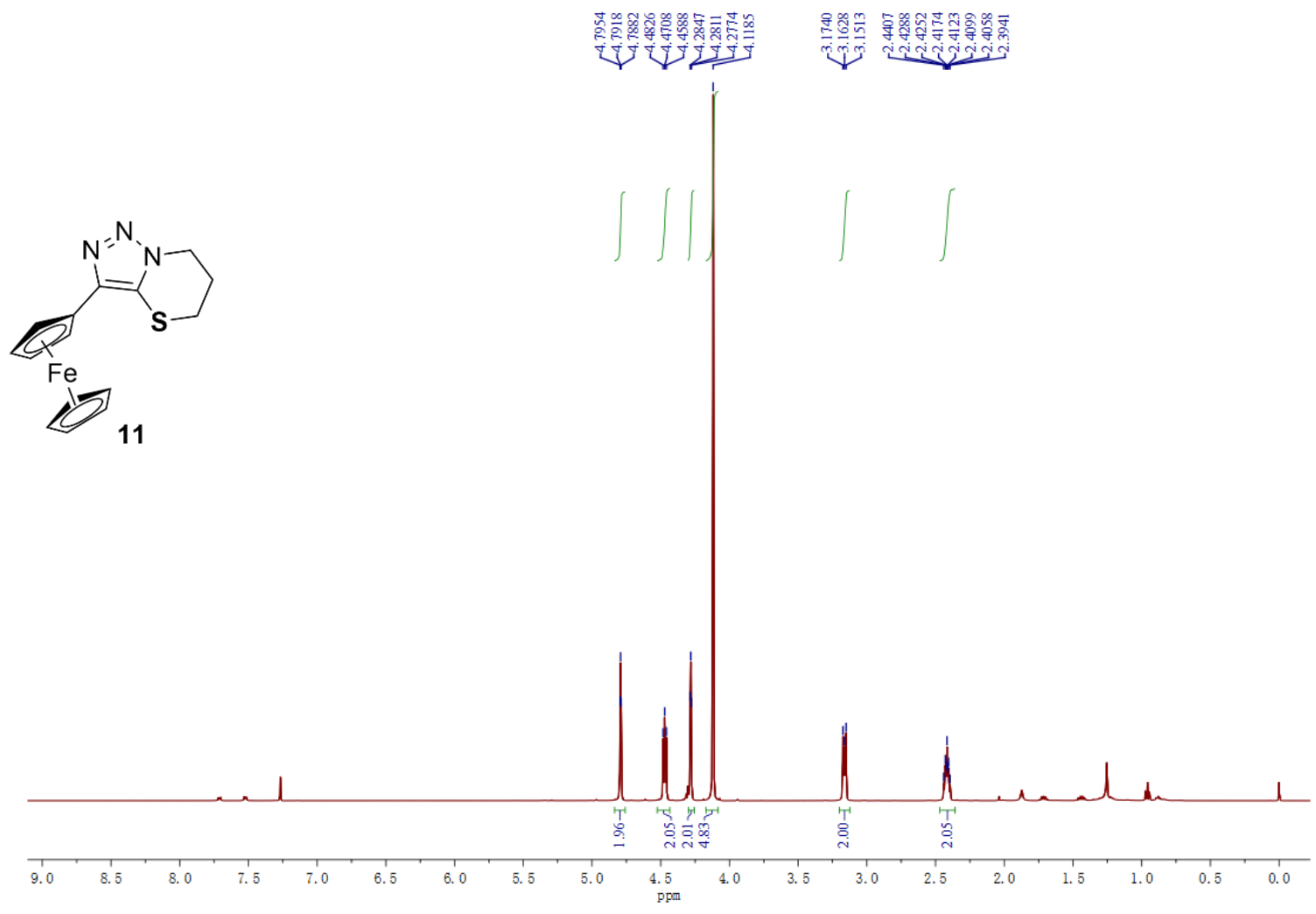

Figure S24. ${ }^{1} \mathrm{H}$ NMR spectrum of compound 11.
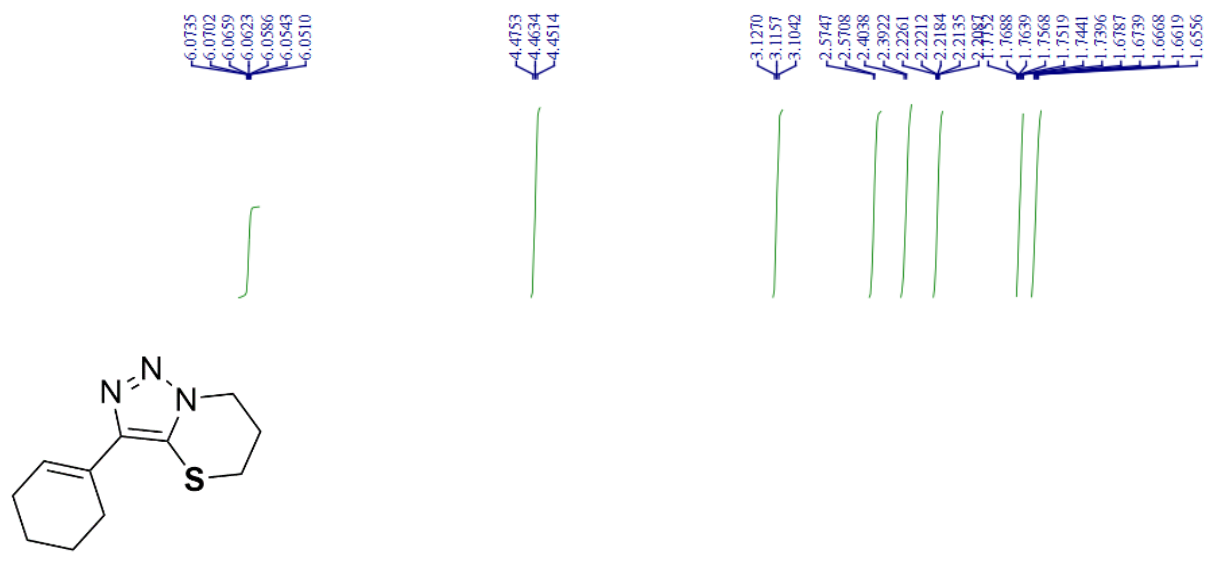

12

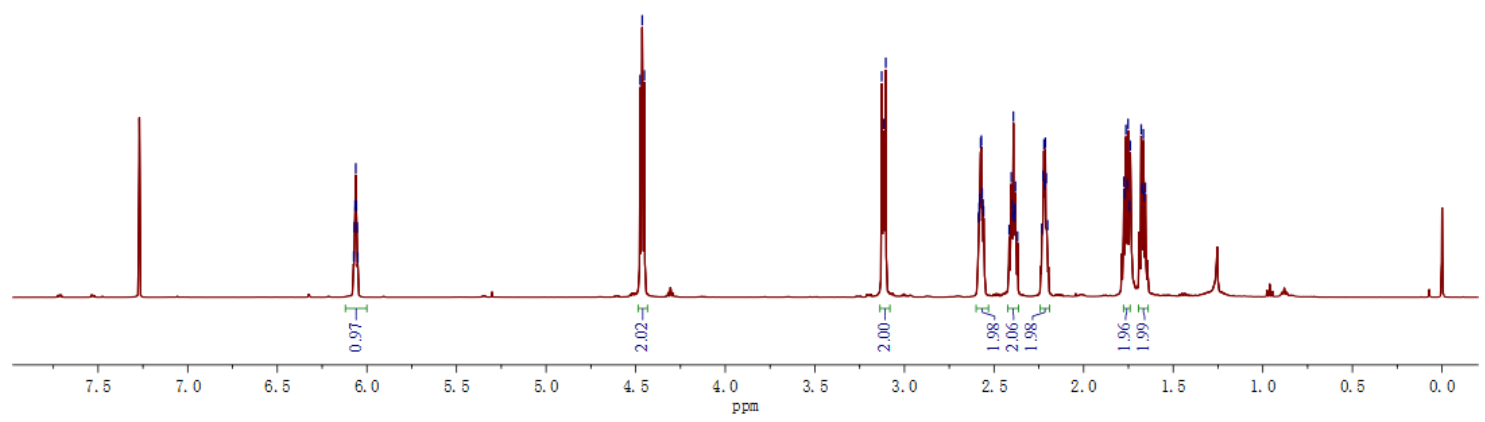

Figure S25. ${ }^{1} \mathrm{H}$ NMR spectrum of compound $\mathbf{1 2}$. 


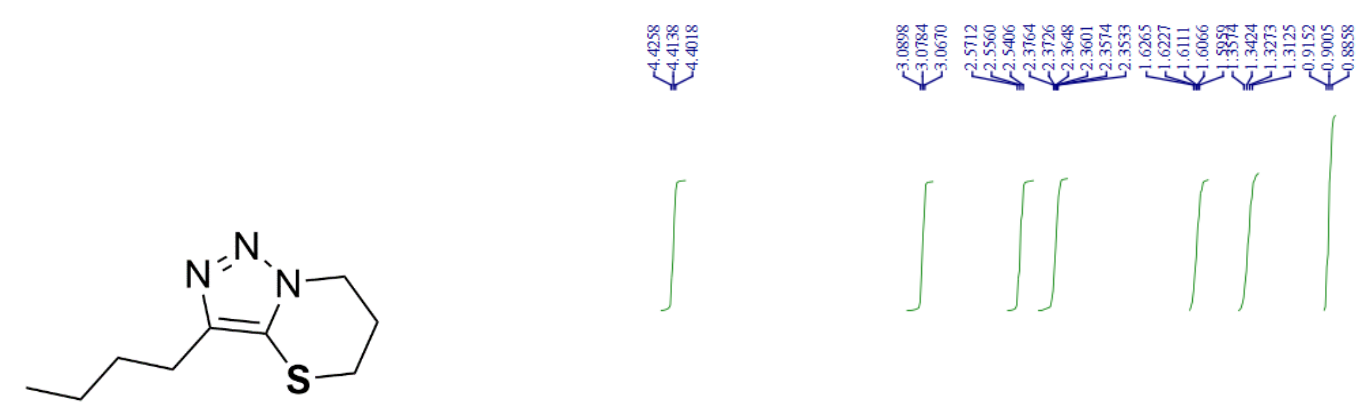

13

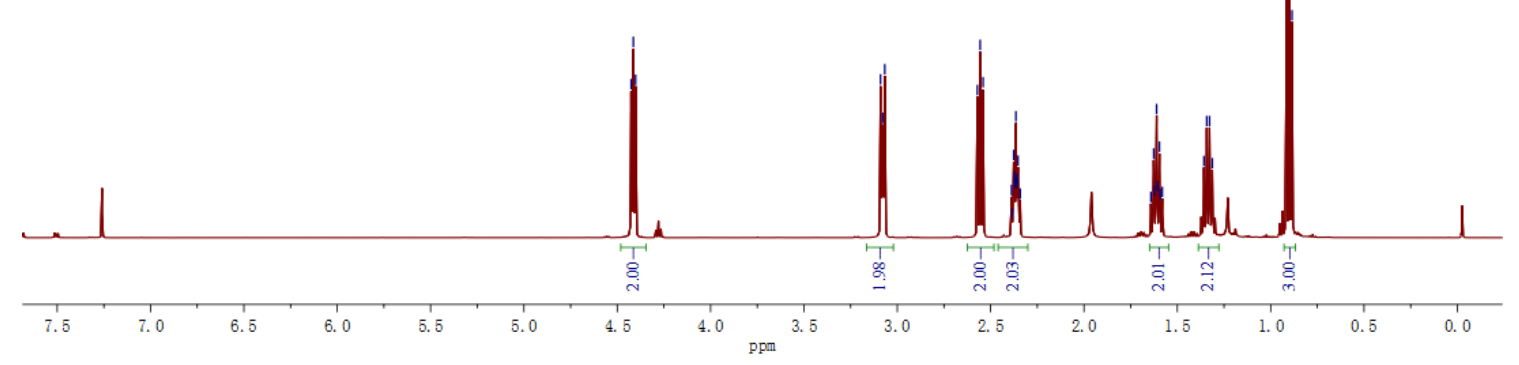

Figure S26. ${ }^{1} \mathrm{H}$ NMR spectrum of compound 13.
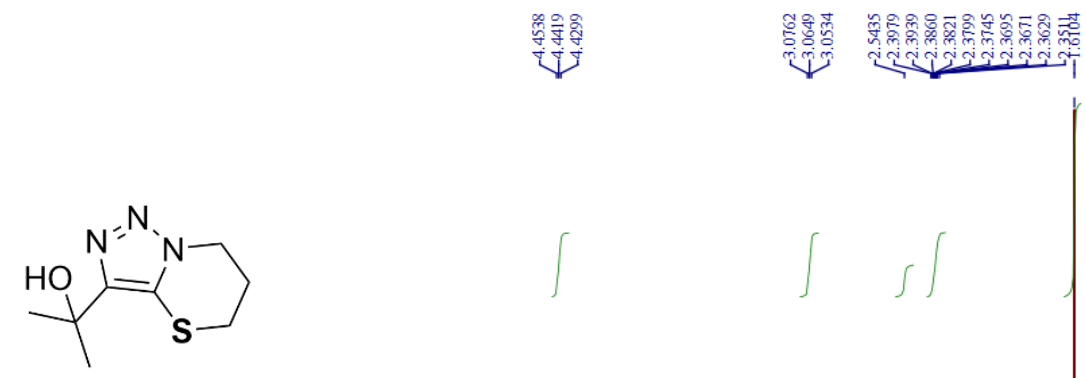

䐱表守

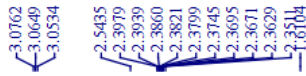

14

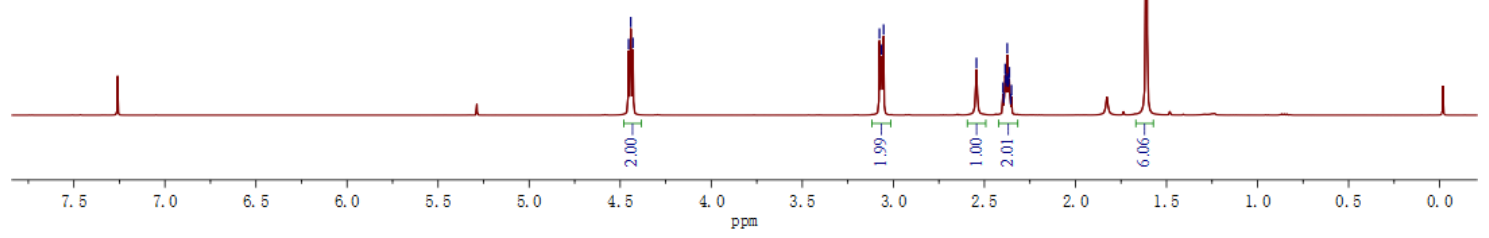

Figure S27. ${ }^{1} \mathrm{H}$ NMR spectrum of compound $\mathbf{1 4}$. 

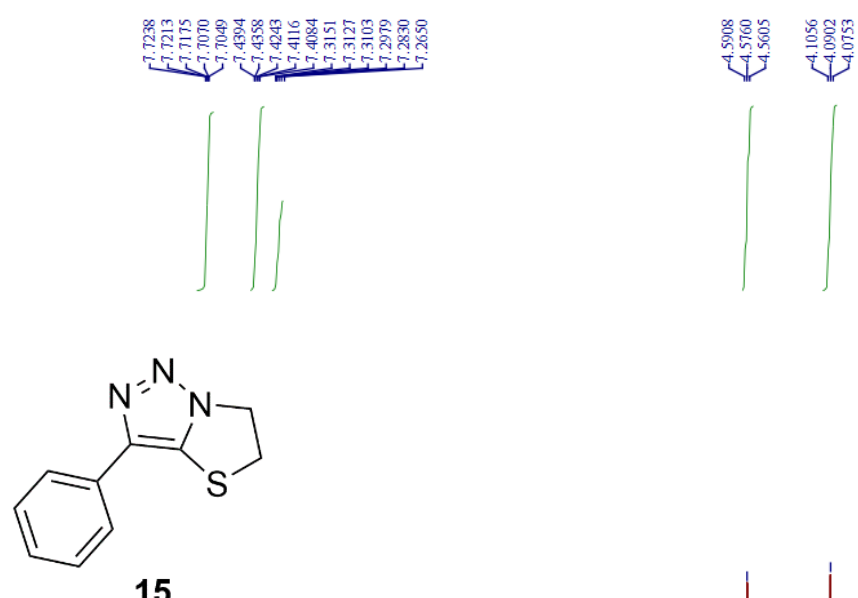

15

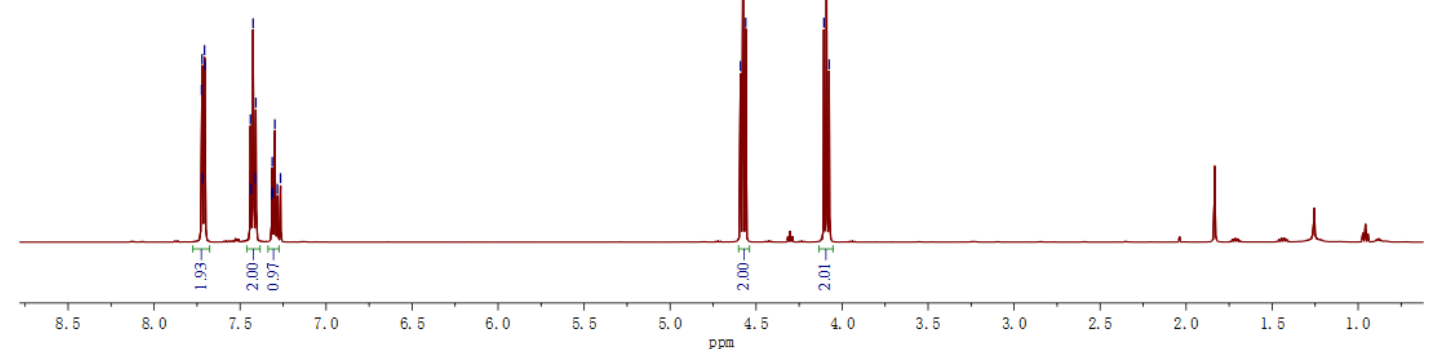

Figure S28. ${ }^{1} \mathrm{H}$ NMR spectrum of compound 15.
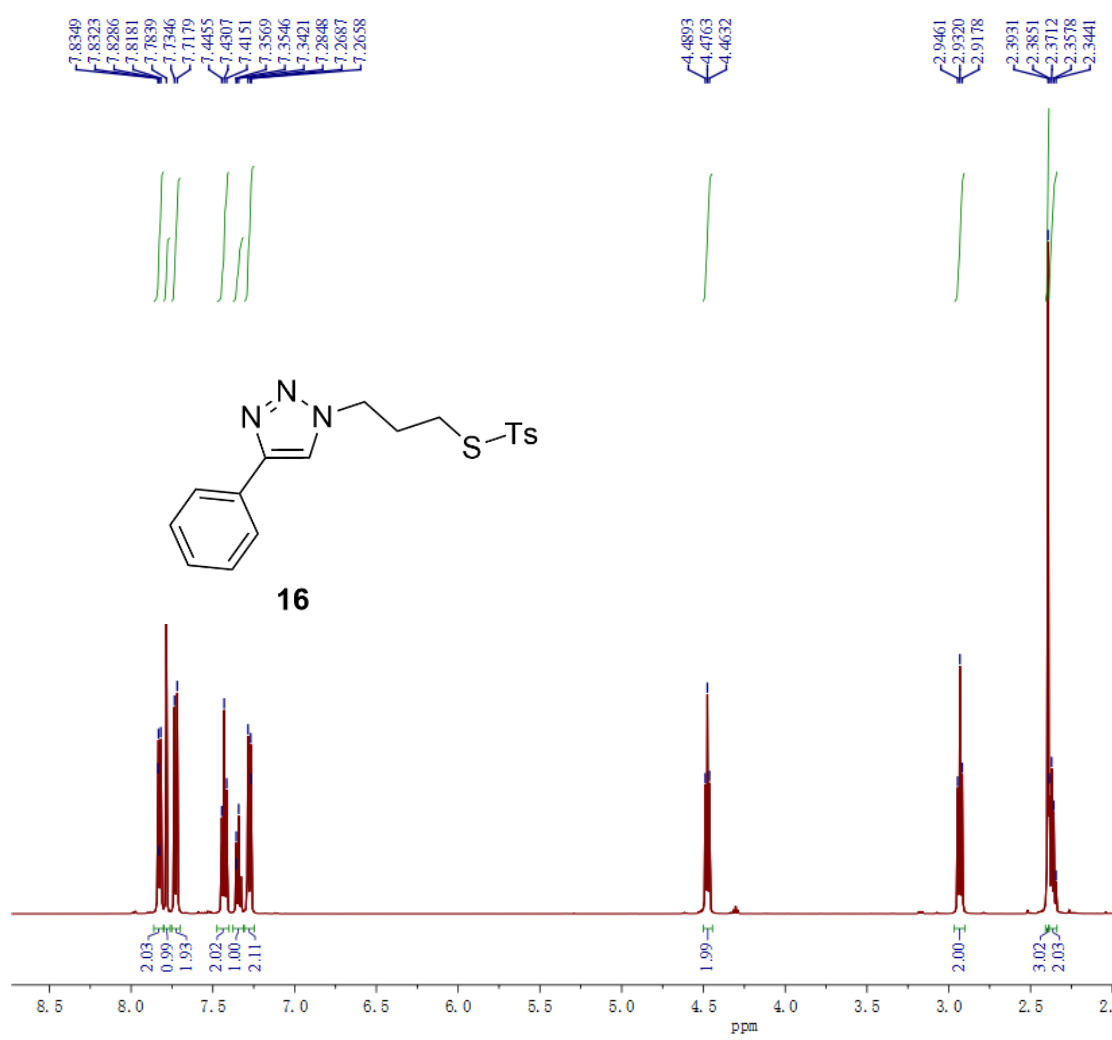

Figure S29. ${ }^{1} \mathrm{H}$ NMR spectrum of compound $\mathbf{1 6}$. 


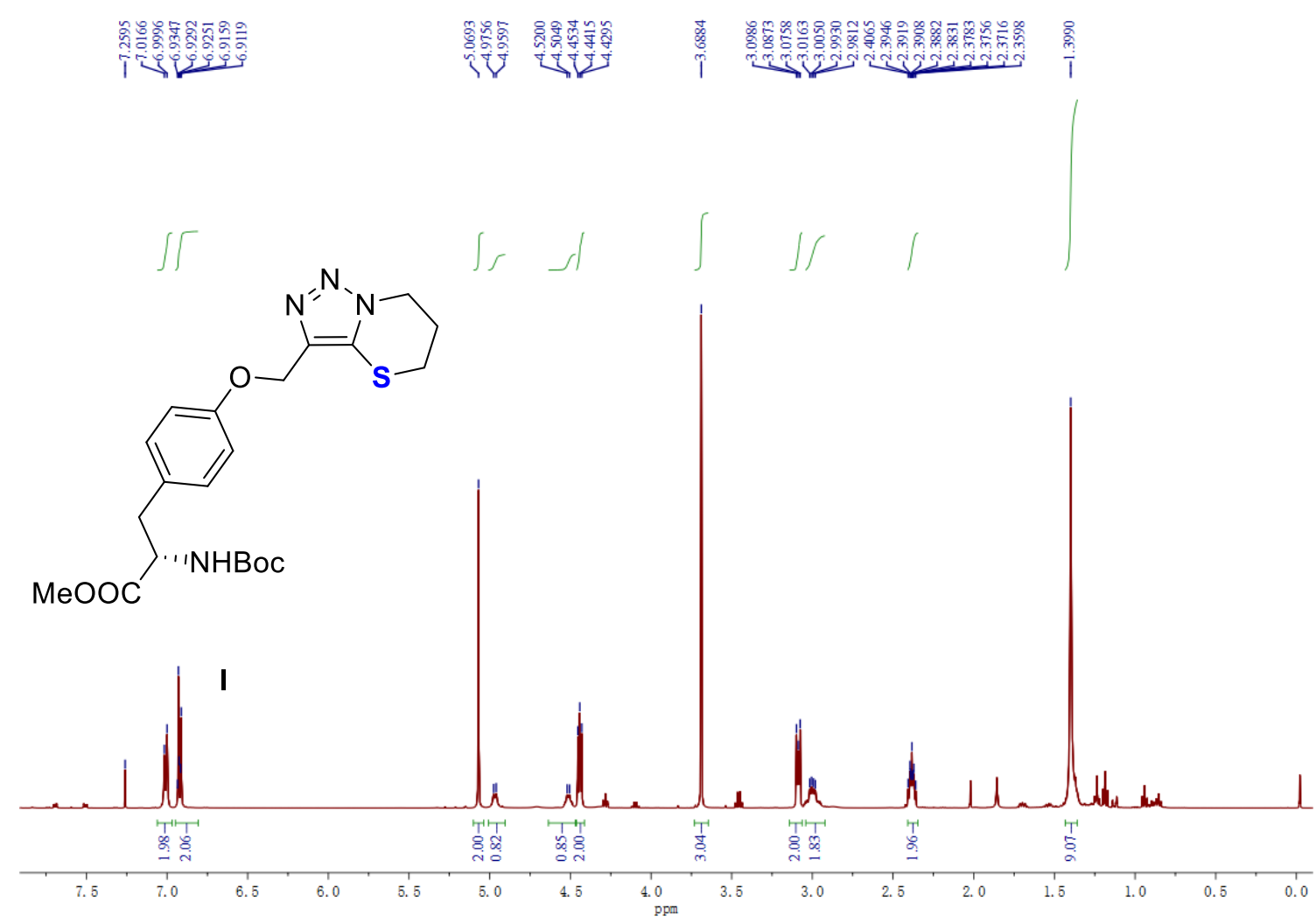

Figure S30. ${ }^{1} \mathrm{H}$ NMR spectrum of compound $\mathbf{I}$.

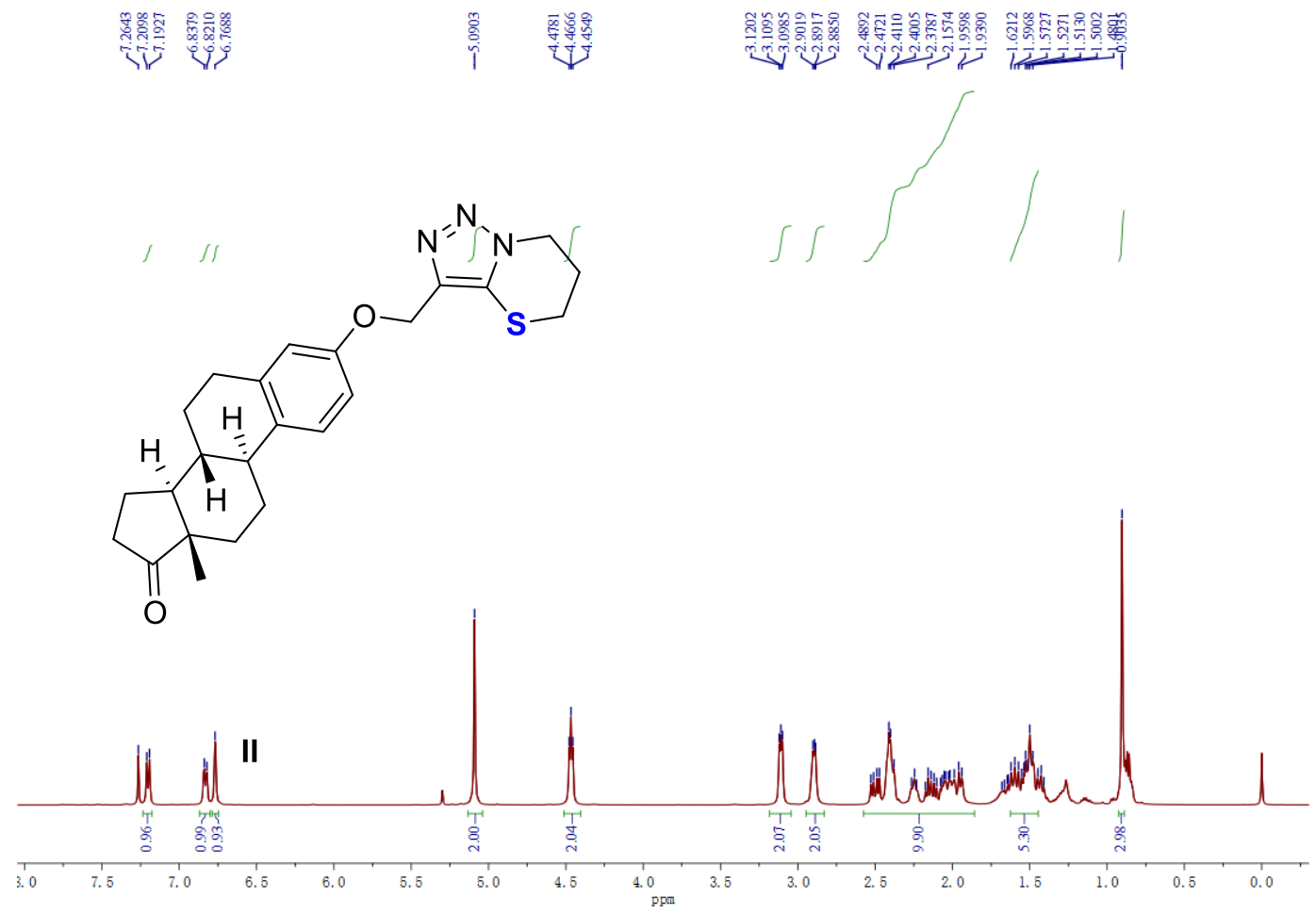

Figure S31. ${ }^{1}$ H NMR spectrum of compound II. 

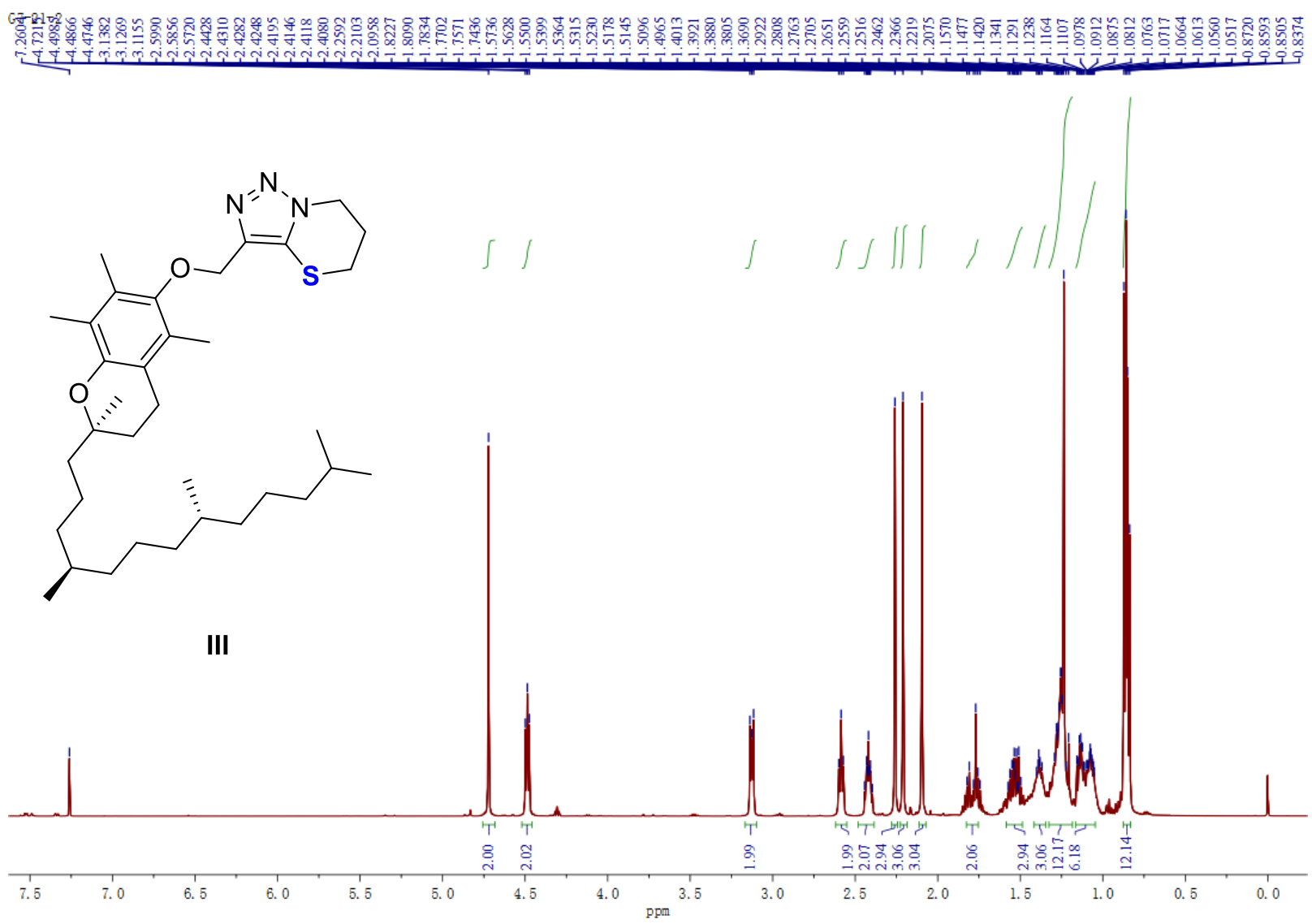

Figure S32. ${ }^{1} \mathrm{H}$ NMR spectrum of compound III. 